\title{
LAPURDUTM
}

Euskal ikerketen aldizkaria | Revue d'études basques |

Revista de estudios vascos | Basque studies review

$1 \mid 1996$

Numéro I

\section{Hitz eratorriak materreren dotrina christiana delakoan (1617)}

\section{Bernard Oyharçabal}

\section{(2) OpenEdition}

Journals

Édition électronique

URL : http://journals.openedition.org/lapurdum/1858

DOI : 10.4000/lapurdum. 1858

ISSN : 1965-0655

Éditeur

IKER

Édition imprimée

Date de publication : 1 octobre 1996

Pagination : 37-71

ISBN : 2-84127-106-4

ISSN : $1273-3830$

Référence électronique

Bernard Oyharçabal, « Hitz eratorriak materreren dotrina christiana delakoan (1617) », Lapurdum [Linean], 1 | 1996, Sarean emana----an 01 septembre 2010, kontsultatu 01 février 2020. URL : http:// journals.openedition.org/lapurdum/1858 ; DOI : 10.4000/lapurdum. 1858

Oyharçabal B. | IKER 


\section{HITZ ERATORRIAK MATERREREN DOTRINA CHRISTIANA DELAKOAN (1617)}

Aspaldi du ohartu zaizkiola euskalariak, bai eta idazleak ere, euskarak atzizkien bidez hitz eratorrien eratzeko eskaintzen duen bideari, eta joera herrikoiak eta hiperkultistak bat egin badute anitzetan maileguei euskarako borten zabal-zabala irekitzeko, aski goiz agertu da, beste aldetik, dela hiztegi egileen artean, dela idazleen artean, kontrako joera ere, euskararen erabide berezkoez baliatu nahiago zutenek bultzatua.

Egiaren aitortzeko, ez bide da egoki gauzak osoki aurkaritza horren arabera aurkeztea, bi jokabideak elkarri bizkarrez baleude bezala, ezen maiz eta maiz eratorbidea hitz mailegatuen hobeki etxekotzeko ere baliatua izan da. Ikusirik, adibidez, erdal adberbio batzuk nola itzuli zituen Leizarraga batek (sumarioqui, exteriorqui, affectionatuqui, eternalqui, specialqui, interiorqui, necessarioki, distinctoqui, purqui, ...), berehala ikus daiteke delako aurkaritza ez dela beti aipatu molde horretan agertzen. Alabaina mailegutzako jokabideetan ezaguna da jokabide bikoitz hau : alde batetik, erran-nahi lexikala dakarren oinarriaren mailegatzea, eta bestetik kategoria emaile den morfema eratorlearen ordezkatzea. Alderantzizko jokabidea ere ez zaigu arrotza, bestea bezain emankorra ez bada ere : handios, adiskidantza, egitate, etab...

Euskarako eratorbideaz egin diren lanen artean bereziki aipatzekoak dira euskararen morfologia ikergai izan dutenak, hala nola, Uhlenbeck (1909), Azkue (1923), Villasante (1974), bai eta gramatika orokor batzuetan aurkitzen diren zenbait kapitulu, bereziki Lafitterenekoak (1944). Ez daiteke erran, hargatik, gai horri buruz testuetan beretan eginikako bilketa lan anitz egin dela, salbuespen bakanen artean MEN eta PEN atzizkiez de Rijk-ek (1991), Oihenarten olerkietako lexiko sorkuntzaz Azkaratek (1992), eta Mitxelenaren euskarazko lan sail batez Perez Gazteluk (1995) ondu lanak ditugularik.

Alde horretarik euskal hiztegi guziak ez dira osoki fidatzekoak. Ezen horrelako lanei behatuz ohart gaitezke bi hizkuntzatako hiztegietan aski alde handia izan daitekeela hitz eratorriei buruz abia hizkuntzaren arabera. Tradizio zaharreko hiztegietan beretan ere, itzulgaia euskarazkoa duten zerrendetan, gutiago dira hitz eratorriak, erdarazko sarrera dutenetan baino (Lakarra, 1994).(1) Eta badakigu geroztik joera hau ez dela baitezpada ahuldu. 
Hitz batean erraiteko eskas ditugu euskal atzizkien hiztegiak, erran nahi baitu, atzizki bakoitzari dagozkion hitzen zerrendak, testuetan beretan oinarri harturik sistematikoki eratuak. Ikerlan hau, hain zuzen, halakoa da, haren helburua baita Lapurdiko idazketa eskolaren hatsarrea seinalatzen duen Materreren Dotrina Christiana (1617) azterkatuz, obra horretako hitz eratorrien bildumaren eskaintzea.

Lehen urrats batean, Materre eta haren liburua hitz laburretan aurkeztuko ditut. Ondotik atzizkien bidezko eratorketaz zenbait puntu, orokor direnak, gogora ekarriko ditut. Gero Dotrina Christiana liburuko hitz eratorrien bilduma, atzizkien arabera eratua, agertuko dut hitz eratorri bakoitzarentzat adibide bat emanez, eta zenbait iruzkin eginez.

\section{Estebe Materre eta haren dotrina.}

1.1. Estebe Materre San Frantziskoren ordenako frantses frailea zen, 17. mendearen hastapenean, liburu bat, erdaraz idatzia naski, publikatu (1606) ondoan ${ }^{(2)}$ Euskal Herrira etorria. Ez dakigu zertara jina zen bazter hauetara(3) eta zenbat denbora egon zen zuzen Lapurdin, baina iduri luke 1617 an jadanik Lapurditik urrundua zela, ezen urte hartan egina den liburuaren onespenean Gilantena Itsasuko erretorak dio ordukotz La Réoleko guardiana zela Materre. Vinsonek (1891), bestalde, salatu zigun zenbait urte geroago, 1623an, Tolosan izanen zela.

Materreri zor zaio mende hartan egin zen euskarazko lehen liburua, lehenbizikoa euskal letretan prosaz egina eta itzulpena ez dena.(4)

Aitzineko hostoetan euskaldunei hitz bat idatzi zien Materrek, hartan esplikatzen baitzuen zergatik, bera Euskal Herrikoa ez izanik, idatzi zuen liburu hura euskaraz ${ }^{(5)}$ : alde batetik sineste katolikoaren irakaspenen azkartzeko euskaldunen izpirituetan, baina, beste aldetik euskara hizkuntza idatzi gisa arautzeko ere : ${ }^{(0)}$

Eta nola lanac cimendutic behar baitu hassi, eta gure salbamenduco obraren cimendua baita Doctrina Christiana, halatan nic ere, handic hasten naicela, hartu dut gogo liburutto hunen eguiteco, eta iendartera atheratceco, hunetan (bertce erakusleric eztenean) ikus dadin laburzqui cer-ere sinhetsi, obratu, eta escatu behar baita; Eta guero ikus dadin halaber nola behar den Euscara esquiribatu eta iracurtu.

Hitz hoiek ikusirik, iduri luke Materrek kontra-erreformaren izpiritua baliatu nahi izan zuela, ez bakarrik fedeari zetxezkion gaietan, baina halaber mintzairari zihoazkionetan ere, aditzera emaiten zuela abisu horretan haren arabera euskara idatzia oraino arautzeko eta finkatzeko zela garai hartan. Frantziskanoaren xedea, hitz batez, euskal mintzaira letrazko egitekoetara egokitzea izan zen, alkitik ahoz peredikatzea ez baitzitzaion aski, eta euskaldunak idatziaren bidez ere fedeko gauzetan nahi baitzituen argitu : Eta etçait iduri asco dela 
Cadiratic predicatuz probetchu eguitea baiña are uste dut esquiribuz ere behar dela enseyatu eta trabaillatu zioen ezin argikiago.

Segurki, aitzineko mendean, Leizarragaren inguruan bereziki, izan zen halako mugimendu bat Euskal Herrian euskararen letra hizkuntza egiteko. Ez dakigu, ordean, lan haiek biziki zabaldu zirenetz Nafarroako errege-erreginek mendean ez zeukaten Lapurdiko probintzian, eta neke da jakitea Erromaren gerizatik hastandu ez ziren apezek, handik berrogei urteren buruan, zenbateraraino balia zitzaketen heresiaren usaina zerien halako irakurgaiak. Haren liburua ikusiz, ez du iduri Materrek begiak Leizarragaren itzulpenetan biziki higatu zituen. Baina horrek Leizarragaren itzulpenak ez zituela batere begistatu erakusten ote du ? Ezin erran, baina iduriak ene ustez ez digu horrelakorik salatzen.

Goragoko aipua ikusiz, batek uste izan dezake orduko euskaldun alfabetatuetan ere arras gutik baizik ez zekiela euskaraz irakurtzen eta idazten. Ez da segur, haatik, gauzak arras horrela konprenitu behar direla. Ezen euskara orduan letra hizkuntza guti arautua bazen ere, hura zatekeen jendeen arteko mintzabide nagusia Lapurdin, idatzian ere baliatua. Argitara eman dira berrikitan Urtubiako andereak 1598an euskaraz idatzi gutun batzuk, Lapurdiko handikiek, behar zutelarik bederen, edo komeni zitzaienean, euskaraz izkiriatzen zutela erakusten digutenak (Floristan Imizkoz 1993). Modu berean, 1620an edo hor nonbait argitara eman zituen Voltoirek euskararen ikasteko bere solasaldiak, Donibane Lohizunen euskara merkataritzako mintzaira gisa ere erabilia zela erakusten dutenak. Segurenaz ere, ordu arte euskarazko liburu guti publikatua izan bazen ere, aspaldi zuen euskara idatzia baliatua zela Lapurdiko gizartean, eta pentsa daiteke euskara zela idazterakoan ere lapurtar anitzi egiazki balia zekiekeen mintzaira bakarra.

Iduripen horren indartzera heldu dira Materrek liburuaren bigarren argitalpenean (1623) eginikako aitzin solaseko hitz hauek :

Eta ceren añhitz baita Euscal-herrian iracurtcen daquienic, baiña ez Euscara baicen bertce hitzcunçaric aditcen, halatan eguin ditut halacoençat Euscaraz debocinozco othoitz eta oracino batçu, goicetan, arratsetan, eta bertce añhitz demboratan eta ocasinotan eguin eta erran ahal ditezqueyenac.

Halaber otoitz batzuk mariñelek beren bidaietan erraiteko eskaintzen baitzituen Materrek bere liburuko ondar partean, ez du dudatzen itsas untzietan euskaraz irakurtzeko gai ziren mariñelak izanen zirela, eta haiek haren otoitz liburua eskuetan izanen zutela :

Eta hauquen ondoan erran beça çuetaric batec [itsasoan dabiltzan mariñelei mintzatuz] appurbat gora eta haguitz orai hemen ibenico dudan othoitza : eta bitartean eduqui beçate bertcec ere hartan gogoa, ençun beçate, edo norc bere liburuetan ixilic iracur beçate, ceren estimatcen dut ez-tela icanen bat-ere iracurtcen daquien marinelic liburu haur içanen eztuenic. (328.o.) 
Materrek liburu bat bakarrik idatzi zuen euskaraz, hemen aipatzen dugun Dotrina Christiana hain zuzen ere. Lehen argitalpena 1617an egin zen, baina Villasanteren (1979) eta Bozas Barrutiaren (1968) arabera ez da gelditzen argitalpen hartako alerik. Bigarren argitalpena 1623 an egin zen, eta hau izan da hemen baliatu duguna ${ }^{(7)}$. Ez da dudarik aski arrakasta handia izan zuela Dotrina honek, mende baten buruan oraindik publikatua izan baitzen. Erran dezagun, bestalde, liburuko pasarte batzuk ondotik baliatu zituztela beste autore batzuek Lapurditik kanpo ere. ${ }^{(8)}$

Liburuaren ikuskatzaileak bi izan ziren : Axular, Sarako erretora, eta Gilantena Itsasuko erretora zena orduan.

Axular hor aurkitzea ez da bitxi, kontuan hartzen badugu Materrek Saran ikasia zuela euskara, eta beraz uste izatekoa dela hango erretora ongi ezagutu zuela. Materrek berak erran zuen non ikasi zuen euskara, gero Axularren lumapean aurkituko ditugun hitzak erabiliz ${ }^{(9)}$ :

Gaiñeracoan ba-daquit Euscal-herrian añhitz moldez minçatcen direla, et nor bere herrico Euscara çaicala hoberenic eta ederrenic: Eta handic gogora emaiten deraut ene esquiribatceco molde haur etçayela guztiei ongui idurituco: Baiña nahi dut iaquin deçaten halacoec nic hitzcuntça hunetan daquidana Saran ikassia dudala, eta hango Euscara ongui erabiltcen ba-dut ez naicela gaitz erraiteco, eta ez arbuyatceco, ceren ez paitaquit nic hangoa baicen. Ordea ea Saraco Euscara denz Euscal-herrico hoberena eta garbiena, ez naiz ni hartan sartcen, bat-bederac emanen du bere iduriric. Eta Saraco Euscara hunetcaz content eztenac ezquiriba beça bertce Euscara hobeago batez eta hobequiago, ez naiz ni hargatik bekaiztuko, eta ez imbidios içanen.

Materrek euskara artez, argi, nekerik eta engainamendurik gabekoa zerabilen, jende xoilentzat egina, baina garbi eta apaina, beti klar eta zituen helburu pedagogikoentzat arras egokia. Ezen Dotrina Christiana, erdi katixima erdi otoitz liburua da, ez gogoeta idazlana, ez eta, are gutiago, hitzaren erran-nahi hertsian edo noblean harturik, literaturazko obra ere.

\section{Ohar orokor zenbait, euskal atzizkien ikerketan kontuan hartzeko diren puntuez.}

Morfologiazko lanetan hitzen barneko egitura ikertzeko hiru erabide bereizten dira : eratorketa (deribazioa ere deitua), elkarketa (konposizioa ere deitua), eta jokadura (flexioa ere deitua). Gu hemen lehenbizikoaz baizik ez gara ariko, edo hobeki erraiteko hartan baliatzen den morfema sail berezi batez, erran nahi baitu atzizkiez. Atzizkiak bereziki ikertu ditugu, euskaran haiek baitute tokirik handiena eratorketan, eta haiek bakarrik izan baitaitezke hitz eratorrientzat kategoria emaile. Ez ditugu atzizki guziak sartu haatik, zeren, multzo berezi bat osatzen dutelakoan, aditz eratorriak ez baititugu gisa hartan zerrendatu; halaber, gibelkako eratorketak ez ditugu kontuan hartu. 


\subsection{Atzizki eratorleak eta elkarketetako osagaiak.}

Nola egiten da atzizkien eta elkarketetan agertzen diren osagaien arteko bereizketa? Teorian bederen, gauzak aski argi dira : atzizkia morfema lotua da, erran nahi baitu hitz gisa bakarrik agertzeko gaitasunik ez duen forma bat, eta elkarketako osagaia, aldiz, morfema libroa, beste ingurumen batean hitz gisa ager daitekeen osagaia. Horrela, guk hemen ikertzen ditugun atzizkien kasuan, GIA atzizkia dela erranen dugu, baina ez LEKU, nahiz bazkagia eta bazkaleku elkarren irudiko hitzak diren erran-nahiaren eta, partez bederen, egituraren aldetik ere. Alabaina GIA morfema ez da hitz betea euskaraz; bai ordean, LEKU.

Haatik, euskal gramatiketan franko molde nahasian aurkeztua da zenbaitetan atal hau. Horrela, Lafitteren gramatikan edo Villasanteren estudioan aldi, bide, gabe, gai, gune eta (k)ide edo zain adibidez, atzizki eratorleen sailean agertzen dira, gorago aipatu irizpidearen arabera nekez horrela egin daitekeelarik, hitz horiek ez baitira morfema lotuak.

\subsection{Eratorbideko atzizkia eta jokadurako atzizkia.}

Erator atzizkiak flexio morfemetarik bereiztea ere beharrezkoa da, gogoan edukiz, bai aditz jokadura, bai izen sintagmen jokadura ere.

Aditz flexioa delarik ez ohi da buruhausterik sortzen, ez funtsezkorik bederen, nahiz hemen ere morfema batzuk doi bat engainagarri gerta daitezkeen batzuetan, hala nola aspektu burutua markatzen duen morfema, edo izen adizkietakoa. Gramatika gehienetan erator atzizkietan sartzen da - $t u$ morfema (eta $-i$ ere), baina ez dirudi hori bidezkoa dela, -tu atzizkia aspektu marka eta alde horretarik aspektu flexioari dagokion morfema denaz geroz ${ }^{(10)}$. Nolanahi ere ez ditugu aditz eratorriak kontuan hartu gure bilketan, ez izen adizkiak ere (erran nahi baitu $\mathrm{T}(\mathrm{Z}) \mathrm{E}$ atzizkia dutenak).

Flexioa ez da aditzetan bakarrik agertzen euskaraz, izen sintagmei dagokien jokadura ere hor baitugu, hala nola kasu markadura. Eta batzuetan honekin ere ager daitezke eratorbidearen eta flexioaren elkarretarik bereizteko zailtasunak.

Ezaguna da, adibidez, nola zenbait hizkuntzalarik, horien artean Mitxelena (1986), kasu adnominalizatzaileak atzizki eratorle gisa kontsideratu izan dituzten euskaraz, nahiz genitibo horiek kasu paradigman sartuak izan diren gramatika tradizioan, eta beraz jokadurako morfemen artean.

Erran gabe doana, auziaren zuritzeko eratorbidea zeri erraiten zaion ikusi beharra da. Gaur egun, lexikoa eta sintaxia atal desberdinetan dauzkaten gramatika ereduetan behintzat, ongi markatua da eratorbidearen eta jokaduraren arteko bereizketa : lehenbizikoa hiztegiaren edo lexikoaren atalari dagokio, eta bigarrena, berriz, modu batean edo bestean, sintasiaren atalari, erran nahi baitu sintagmen arteko erlazioak josten diren mailari. 
Lexikoaren mailan egiten baita eratorketa, lexikoko unitateetan obratua da, esan nahi baitu hitzetan beretan. Hortik ondorio hau : eratorletasuna ez dagokie izen sintagmei eransten zaizkien morfemei, baizik ere hitz hutsek -izan daitezen bakunak edo ez- hartzen dituztenei.

Irizpide gisa balia dezakegu puntu hau, sintagmei darraizkien atzizkiak eratorbideko eremutik kanpo uzteko, hala nola kasu markak (genitiboak barne), edo tzat prolatiboa. Duda gelditzen da, haatik, beste zenbait atzizkirentzat. ${ }^{(11)}$

Batzuetan argi da hitza dela atzizkiaren eremua (TSU edo OS izenondo sortzaile diren atzizkientzat, adibidez, edo KI aditzondo eratzailearentzat), baina DUN bezalakoak maila berekoak ote dira ? Segur atzizki horiek ez dute edozein sintagma selekzionatzen, eta bereziki ez determinatzailerik duenik, baina hitz hutsetara soilik eransten zaiea ?

Horrelako morfemen izaera ez da garb: euskaraz, ezen, iduriz, euskaldun guziek ez dituzte berdin onartzen ondoko adibideak (Leizarragaren idazlanetan ageri direnak):

\section{??/\%/+ begi bakoiztun / esku bakoitzdun / \\ ??/\%/+ esku eihardun}

Hegoaldeko hiztunek ere aise onartzen dituzte [[atorra eta galtza] gorridun] haurra bezalako itzuliak, bizkitartean beste batzuentzat doi bat bortxatuak direlarik. Erran gabe doa, gaitasun gramatikal horren arabera nekez DUN erator atzizki gisa kontsidera daitekeela, cf. Odriozola eta Zabala (1994).

Azken urteetan gramatikako hiztegia gehienik moldatua izan den hizkuntzetan preposizio edo posposizio deitura baliatu da [- IZENA ; - ADITZA] ezaugarriak dituen kategoria lexikal nagusiaren izendatzeko. Haatik, azken deitura honek unitate horien forma kontuan hartzen du egiazki, eta ez haien kategoriazko izaera. Erran nahi baitu, izan daitezkeela, eta badirela, kategoria horretako morfemak atzizkien bidez adieraziak (bai kasu atzizkiak, bai bestelakoak). Euskaran posposizio atzizkiak erran diezaiekegu halakoei, proiekzio sintagmatiko bateko buru gisa azter daitezkeenak eta, ondorioz, atzizki eratorleetarik bereizteko direnak.

Seinala dezadan azalpen horiek bururatu gabe, -ago eta -egi atzizki konparatiboak ere posposizio atzizkitzat jo ditudala eta ez eratorbideko hizkitzat. Alabaina atzizki horiek atzizki eratorriak ager ez daitezkeen ingurumenetan kausitzen dira (handitzenago), eta nekez ene iduriko lexiko mailako morfema gisa har daitezke lexikoan agertzen diren zenbait kasu berezitan ez bada (on ---> hobe).

\section{Materrerek erabili atzizki eratorleak.}

Agertzen diren atzizkiak : antza, ari (1), ari (2), dura, garri, ka, (k)eria, (k)eta, ki (1), ki (2), (k)izun, (kh)oi, kuntza, le, mendu, os, pen, ro, tasun, ti, tsu, to, tza, tzaile, tze, zale, zarre, zia. 
Ordena alfabetikoan aurkezturik, atzizki bakoitzaren bidez sortu hitzen zerrenda eskainiko dugu, aldi bakoitz adibide bat emanez, eta ondotik iruzkin labur batean, atzizkiaren bidez sortu hitz eratorrien eta haien oinarriaren kategoriak mugatuz. Hitzaren aurkezterakoan ortografia gaurkotu dugu (salbu, maileguei buruzko jokabideen segitzeko edo morfologia gardentasunarentzat ondoriorik izan zezakeenean), baina adibideetakoa zen bezala utzi. Idazlanaren ondarrean, eranskin batean, corpuseko hitz eratorriak ordena alfabetikoan bildurik aurkituko dira, itzulpena ondoan dutela.

Barianteak, eta hitzen barneko atzizkiak kontuan hartu gabe, 178 hitz eratorri desberdin, adizki bati ez dagozkionak, zenbatzen dira.

\section{ANTZA}

a!egriantza : Ceren çu çara ene esperança, ene bicitcea, ene erremedioa, ene arguia, ene borthitztasuna, ene aberatstasuna, ene consolamendua, ene alegriança, ene atseguina, ... (264.o.)

ANTZA atzizkia beste bi hitzetan ere agertzen da : esperança eta segurança. Ordean, nola hitz horiek espainolean ere kausiten baitira, kontsidera daiteke hitz osoak izan direla mailegatuak.

Alegriança hitzaren kasua desberdina da, ezen forma hori, iduriz, ez da agertzen ondoko erromantzeetan.

ANTZA-ren kide erromanikoa kausitzen da Corominasek aipatzen digun espainol zaharreko alegranza forman, eta beste modu batean gaskoinez ere alegrance hitzean (ik. S. Palayren hiztegia). Euskaraz ere, maileguaren bidez bide horri segituz, alegrantza hitza agertzen da (Leizarragak eta Gazteluzarrek, adibidez, zerabilten).

Ordean, alegriantza eratorria denaz bezainbatean, nola alegria hitza ez baita agertzen lapurtar idazleetan (bai, aldiz, Etxepareren bertsue$\tan$ ), pentsa dezakegu ANTZA atzizkia alegria oinarriari lotua izan zaiola lapurteran maileguaren hobeki etxekotzeko, gorago aipatu jokabidearen bidez. Lapurtar idazleek izenondoarentzat alegera forma zuten (Materrerek erabiltzen ez badu, bai, ordean, Axularrek, Etxeberri Ziburukoak, S. Pouvreauk ..., Leizarragak bezala). ${ }^{(12)}$

ARI (1)

gidari : Ezagutcen dut ecen çu çarela ene bicitçearen gobernaria, espirituaren guidaria, adimenduaren arguitçailea (...). (293. o)

gobernari : Hunequin batean gomendatcen derauzquiçut munduco estatu guztiac, (...), Eliçaco bertce Superiorac eta Gobernariac, Gure Erregue Jauna, (...). (220. o)

urrikari : Hec dira bihotz-berac, beharrean daudenac, urricari dituztenac, eta bere ahalaren arauaz onez ere faboratcen ituztenac. (150. o.)

zerbitzari : Abraham çure cerbitçari leyala Caldeanoen escuetaric libraturic bere bide guztietan beguiratu baitcenduen. (334. o) 
ARI atzizki agentiboa, izenei eta aditzoinei lot dakieke. Batzuetan, ordean, zail da jakitea nola den kasua zeren aditzoina eta izena, bata nola bestea, izan baitaitezke oinarri. Nahiz hemen ere bi hitzetan bi oinarriak posible diren teorian (ZERBITZU / ZERBITZA ; GOBERNU ( GOBERNA), GIDARI hitzean ez da horrela. Hiru hitzetan aditzoina dateke oinarria, ez hari doakion izena.

Urrikari hitza urrikari ukan lokuzioan agertzen da corpusean, eta izen kategoria du. Ez da beti argi zer adierazten duen zuzen : urrikia bera, edo urrikia sortzen edo erakartzen duena. Ühlenbeck-ek digne de pitié itzultzen du, eta qu'on plaint Orpustanek (1993) Oihenarten obraren hiztegian, baina Axularrek bestelako balioa emaiten dio arrainaren urrikariz dioenean (\$330). Azken kasuan nahikari edo ustekari hitzetan bezala IZENA + KARI erabidea genuke. Ordean, urrikari zaitut bezalako formetan azterketa hau nekez onets daiteke. Beste interpretazioa hobetsiz, berriz, nolabaiteko balio 'aktiboa' luke atzizkiak, aditz psikologikoen edo afektiboen kasuan horrelako terminologiarik erabil badaiteke. Horregatik, segurtamenik batere gabe, zerrenda honetan sartu dugu hitza, URRIKI + ARI azterketa proposatuz (urriki izena izanik, edo aurreko paradigmari jarraikiz, aditzoina).

\section{ARI (2)}

edari : Egarri ba-naiz, çu çara edaria eta ithurria. (277. o)

ARI (2) atzizkia, jan-edanari lotua dena (cf. afari, askari, gosari, janari, etab...), behin baizik ez da agertzen zerrendan. Oinarria aditzoina da, kasu honetan ondarreko - $n$ galdurik (cf. alderantziz jan (h) ari). Atzizki hau bakarrenetarik da zerrenda honetan eihartutzat jo dezakeguna.

\section{DUN}

euskaldun : Euscaldunei (aitzin oharra).

DUN atzizkiaren bidez sortu hitz bakarra da gure corpusean euskaldun. Gorago erran bezala, zenbait hiztunentzat bederen, DUN posposizio atzizki gisa ere har daiteke. Ez da argi nola ziren gauzak Sarako orduko euskaran.Axularrek konparazione ez du sekula Leizarragak bezala egiten, -dun atzizkia [IZENA + IZENONDOA] taldeari lotuz.

\section{DURA}

herstura : ceure botherearen faborea egor diaçaguçu herstura handi hunetan. (357. o)

izialdura : Noiz behar da ceiñatu ? - (...) cembait icialdurac hartcen gaituenean, (...) (44. o)

nothadura : eta halatan sortcen gara likistuac eta nothatuac: eta nothadura hura deitcen da becatu originala. (162. o.)

oliadura : Eliçaco Sagaramendu sainduac dira çazpi : (...) 5. Oliadura, edo Anuncioa. (17. o) 
DURA atzizkia aditzoinei eransten zaie komunzki, eta izenak eratzen ditu. Erdal jatorrizkoa izanagatik (frogarik behar balitz, ohart zubereraz [ü] dela, ez [u], ondotik/r/ izanarren aiphadüra, ekhardüra, ...), osoki sartua da euskal morfema gisa. Materreren hitzetan, herstura eta nothadura hitzentzat ez da dududarik HERTS, NOTHA aditzoinak direla oinarrian.

Oliadura izenak OLIA aditzoina duke oinarria. Nahiz ez Leizarragak, ez Axularrek ez duten aditz hori erabiltzen, Beriaynen (Dotrina-n) (1626) agertzen da garai bertsuan (Sarasola 1984-1995, oliatu sarrera)).

Izialdura hitza ere agertzen da. Haatik, buruhausteak sortzen ditu hitz horrek oinarria finkatzeko orduan. Alabaina IZI(TU) aditzetik izidura forma eratorria, Leizarragak erabiltzen zuena, igurikatzen da, eta ez izialdura. Bizkitartean, hau da gaur egun Axularren garaian bezala gehienik erabiltzen den forma. Oinarria IZIALDI + DURA elkarketa ote da, Lhanderen hiztegian proposatzen den bezala? Erabide hau maizkoa ez bada ere, beharbada baluke paralelo bat ukhaldura forman 'zauria' edo 'ubeldura' adierazteko (Leizarraga) : UKHALDI + DURA. Agud \& Tovarrek (1989), Mitxelenari jarraikiz, IZI + ARDURA (azken hau mailegu garbia delarik), disimilazio batekin ikusten dute. Orduan hitza zerrendatik kentzekoa litzateke, ez bailitzateke DURA atzizkia. Ene iduriko, halere, kontua ez da biziki garbi.

Tristura hitza ere agertzen da (ene espirituaren tristurac khen itçaçu ceure consolamenduaz (283. o)), baina hitza osoki mailegatua izan balitz bezala hartzea komeni bide da.

Seinalatzeko da hitz osoki maileguetan -tura forma atxikitzen duela Materrek (kreatura), Axularrek bezala, eta beraz DURA atzizkiaren hatsarreko herskariaren ahoskabetzeko arrazoinik ez bada (herstura) argi dela maileguen eta euskal erabideari darraizkion hitzen arteko bereizketa.

\section{GARRI}

hilgarri : Cer erran nahi du mortal hitz hunec? - Lecu hunetan hanbat nola hil-garria. (163. o)

miretsgarri : Aithortcen dut, Iauna, ecen ceure pietate handiac, (...), eraguin deratçula miretsgarrizco obra haur. (260. o)

nardagarri : Baiña çuc nolatan (...) nahi duçu hain leku liçunean eta nardagarrian, (...), sarthu? (252. o)

GARRI atzizkia aditzoinei lotzen zaie. Corpusean izenondoak dira GARRI atzizkia dakarten hitz eratorriak (atzizki horrek izenak sor ditzakeelarik bestalde), HIL, MIRETS, eta NARDA aditzoinak izanik oinarriak. Erran nahiaren aldetik prozesuaren eragileari dagokio atzizkia. Halatan, hilgarri hil dezakeenari dagokio adibidean, ez hil daitekeenari ; erran nahi aktiboa du, beraz. 
KA

besarka : Ezconduac eztirenen arteco haraguizco obrac, eta are guehiago bessarcac, musuac, eta bertce desonhesqui huquitce guztiac ere bekatu direla (114. o)

KA atzizkia behin baizik ez da agertzen corpusean. Mitxelena zuzen ari bada hitz horren azterketan : BESO + HAR-KA genuke erabidearen hastapenean KA atzizki adberbiala har aditzoinari lotua izanik (cf. joka, erranka, ikuska, ...), baina erran gabe doa, besarka hitzean forma adberbiala izen gisa lexikalizatu dela. ${ }^{(13)}$

\section{(K)ERIA}

falseria : Eztugula halaber contüan, pisuan, neurrian, sal-erossietan, auenicoetan, eta bertce hartu-emanetan falseriaric edo enganamenduric eguin behar, (...). (115. o)

gaixtakeria : Cure ontasuna eta emetasuna narritatu dut neure gaixtaqueria handiez. (226. o.)

(K)ERIA atzizkia izenei edo izenondoei erantsirik izenak moldatzen ditu, kasu gehienetan gaitzespen marka bat emanez hitz eratorriari. Faltseria Etxepare eta Leizarragak enplegatzen zuten, bai eta 17. mendeko lapurtar idazleek ere, geroztik faktsu/o-keria forma nagusitu bada ere. Oinarria faltso izenondoa (cf. falsoki) da, hala nola gaixtakeria hitzean, gaixto baita.

\section{(K)ETA}

gogoeta : behar dugu arrats guztiaz gueure conciencia examinatu, eta cer eguin, erran, eta pensatu dugun eguin gogoeta. (307. o)

(K)ETA atzizkia gogoeta hitzean baizik ez da agertzen corpusean, gogoeta egin lokuzioan, izen kategoria duelarik.

Badirudi izena dela oinarria gogoeta hitzaren kasuan, nahiz gogo izenaren ondoan, gogoatu aditza ere baden bestalde.

KI (1)

abantaillatukiago : Ceren nola bertce saindu guztiac baiño gayago baitcen, hala bertce guztiec baiño abantaillatuquiago Espiritu sainduaren dohaiñac eta garaciac ere içan baitcituen. (94. o.)

agertuki : Noiz ikussico çaitut bada aguertuqui, eta estalquiric gabe, Ainguerüec cerüan ikusten çaituzten beçala? (256. o.)

ahalkegabeki : Ni naiz bekatore guztietaco handiena, gaixtoena, eta esquer-gabena, ahalque gabequi bici içan naiçena, ... (224. о.)

ansigabeki : Accusatcen dut neure esquergabetasuna, ceren hain laxoqui eta ansicabequi utci dudan aita ona eta amoriozcoa. (226. o.)

atentoki : Meça errailea a[I]darera ethor dadinean, erraçu debotqui eta attentoqui othoitz haur. (194. o.) 
banoki : Nola aditcen duçu bigarren manamendua, Arneguric, cineic, edo iuramenturic vanoqui eta premia gabe eguiten dugula? (109. o.)

beregainki : Esquerrac eta laudorioac emaiten derauzquitçut çure ganic orai artean errecibitu ditudan ontassun guztiez, eta beregainqui ceren ioan den gauean peril guztietaric beguiratu bainauçu. (183. о.)

bereziki : Baiña bereciqui esquer derautçut ceren egungo egun hunetan (...) munduco periletaric beguiratu bai-nauçu. (311. о.)

bidezki : Argui eçaçu bada othoy ene espiritua eta memoria ceruticaco arguiaz, halaco moldez non neure becatuen itsusitasuna, handitasuna eta pisutasuna eçaguturic, cofessa ditçadan librequi, clarqui, eta bidezqui. (233. о.)

borthizki : Bigarrena, Pilatusen etchean harroin batequin loturic borthitzqui açotatu çutenean. (189. o.)

debotki : Eta guero Cofesorac ordenatcen derauzquigun satisfacinoac edo penitenciazco obrac behar ditugu ossoqui eta debotqui complitu. (135. о.)

desoneski :... eta are guehiago bessarcac, musuac, eta bertce desonesqui huquitce guztiac ere bekatu direla. (114. o.)

digneki : Baiña norc erran ahal lę̧aque cembat probetchu, eta ontasun e[t]horcen çai[c]an dignequi, eta behar beçala errecibitcen çaituen arimari? (261. o.)

egiazki : Sinhesten dut oguiaren eta arnoaren iduriaren azpian daudela eguiazqui eta errealqui Iesu-Christo gure Iaunaren gorputz sacratua. (130. o.)

errazki : Eta examinatce hunen errazqui eguiten ikasteco, emanen deratçut hemen molde bat, eta nahi nuque huni iarraiqui bacenenquiţ̧a. (309. o.)

errealki : Sinhesten dut oguiaren eta arnoaren iduriaren azpian daudela eguiazqui eta errealqui Iesu-Christo gure Iaunaren gorputz sacratua. (130. o.)

espiritualki : Eztut guehiago becatu mortalaz espiritualqui hil nahi. (243. o.)

faltsoki : Aditcen dut eztugula nehor falsoqui acusatu behar, ... (116. o.)

finki : Deliberatcen dut finqui eta fermuqui (...) ez guehiago bihurtcera, eta ocasinoetaric ihes eguitera, ... (236. o.)

fermuki : Deliberatcen dut finqui eta fermuqui (...) ez guehiago bihurtcera, eta ocasinoetaric ihes eguitera, ... (236. о.)

gaizki : Huna cein gaizqui emplegatu dudan çuc ongui eguiteco eman derautaçun dembora. (314. o.) 
generalki : Lehena da Iaincoari esquerren emaitea haren ganic generalqui errecibitu ditugun ontasun guztiez. (307. o.)

hobekiago : Declara eçaçu hobequiago cer ondasun diren galdeguiten ditugun laur ontasun horiec. (87. o.)

humilki : Adoratcen çaitut humilqui neure indar guztiaz ... (183. o.)

klarki : Argui eçaçu bada othoy ene espiritua eta memoria ceruticaco arguiaz, harlaco moldez non neure becatuen itsusitasuna, handitasuna eta pisutasuna ę̧aguturic, cofessa ditçadan librequi, clarqui, eta bidezqui. (233. o.)

komplituki : ... eritasunac sendatcen dira, beckatuac (sic) barcatcen dira, eta Espiritu sainduaren dohaiñac complituqui emaiten dira. (261. o.)

komunzki : ..., ceiñec eguiten baitu Eliça bicia, comunzqui Eliça Catholica deitcen den. (66. о.)

laburzki : Non daude sinhetsi behar ditugun gauçac? Credoan laburzqui bilduric. (51. o.)

laxoki : Accusatcen dut neure esquergabetasuna, ceren hain laxoqui eta ansicabequi utci dudan aita ona eta amoriozcoa. (226. o.)

libreki : Argui eçaçu bada othoy ene espiritua eta memoria ceruticaco arguiaz, harlaco moldez non neure becatuen itsusitasuna, handitasuna eta pisutasuna eçaguturic, cofessa ditçadan librequi, clarqui, eta bidezqui. (233. o.)

ongi : Eta handic gogo[r]a emait[e]n deraut ene esquiribatceco molde haur etcayela guztiei ongui idurituco. (Euscaldunei)

osoki : Eta guero Cofesorac ordenatcen derauzquigun satisfacinoac edo penitenciazco obrac behar ditugu ossoqui eta debotqui complitu. (135. о.)

pausatuki : Guero has çaite[z] pausatuqui zazpi oracino hauquen erraiten. (196. o.)

pazientki : Bide-gabeen pacientqui pairatcea. (21. o.)

prinzipalki : Beguira naçaçu peril guztietaric, etsai gaixtoaren enganamenduetaric, eta principalqui bekatu mortaletan erortcetic. (187. о.)

sainduki : Erabil bedi sainduqui çure icena. (88. о.)

xeheroki : ... pensa eçaçu (...) cer obra eguin duçun, geheroqui egiten duçula gogoeta cer becatu eguiten ahal duqueçun. (313. o.)

KI (1) atzizkiak adberbioak sortzen ditu, eta biziki emankorra da, goiko zerrendan ikus daitekeen bezala. Oinarria izenondoa da gehienetan, partizipio batetik sortua batzuetan (abantailatuki, agertuki, konplituki, pausatuki). Izena da, haatik, corpuseko bi kasutan : bidezki, egiazki.

Behin RO atzizki adberbiala aurkitzen da oinarriaren ondarrean, KI doblean agerturik : xeheroki. 
ZKI forma hitz eratorri hauetan agertzen da : bidezki, egiazki, komunzki, laburzki, baina baliteke lehenbiziko bi kasuetan -z- instrumentala izaitea KI-ren aitzinean.

KI (2)

ethorki : Ceren nola Adamec becatu eguin çuenean likistu eta nothatu baitçuen bere ethorquia eta naturaleça, eta guztioc baicara haren ethorquitic eta naturaleçatic, ... (162. o.)

iaki : Ha cerüetaco iaquia! (265.o.)

KI (2) atzizkiak izenak sortzen ditu, eta aditzoin bati lotzen zaio. $\mathrm{Bi}$ adibide baizik ez dira agertzen corpusean.

\section{(K)IZUN}

bark(h)akizun ${ }^{(14)}$ : Eta venial bertce hitz hunec cer erran nahi du? Hambat nola barkaquiçuna, errazqui barkatcen den bekatua. (164. o.)

ethorkizun : Bigarrenean erraiten diogu beguira gaitçala ethorquiçuneco gaitcetaric. (90. o.)

(K)IZUN atzizkia bitan baizik ez da baliatua corpusean, aditzoin bati eratxekirik. Kasu batean izenondo baten moduan agertzen da venial-en parean, bestean izen gisa (ethorkizun).

\section{(KH)OI}

emakhoi- : Haraguizco bekatua, edo emakhoitasuna. (26. o.)

$(\mathrm{KH}) \mathrm{OI}$ atzizkia izenei lotzen zaie zaletasuna adierazten duten izenondoen moldatzeko. Materreren adibidean, $(\mathrm{KH}) \mathrm{OI}$ atzizkia hartu duen eratorriari (eme) beste atzizki bat erantsi zaio: TASUN.

\section{KUNTZA}

hitzkuntza : Eta ceren añhitz baita Euscal-herrian iracurtcen daquienic, baiña ez Euscara baicen bertce hitzcunçaric aditcen (Iracurcailleari).

KUNTZA ere behin baizik ez du baliatzen Materrek, oinarria izena delarik (eta ez aditzoina aldakuntza, bereizkuntza, eta horietan gertatzen den bezala). Ez du kasu honetan prozesu bat adierazten.

\section{LE}

begirale : Aingueru beguiraleari eguiteco othoitça (292. o.)

begiraille : Ezagutcen dut ecen çu çarela (...) beharretan faboratçaillea, periletan beguiraillea, arduraco ongui eguilea (...). (293. o.)

egile : Sinhesten dut Iainco Aita bothere guztia duena, cerüaren eta lurraren eguilea baithan. (3. о.)

emaille: Aithortcen dut çu çarela ene Creatçaillea, (...), ontassun guztien ithurria eta bai emaillea ere. (183. o.) 
erakusle: Hunetan (bertce eracusleric eztenean) ikus dadin laburzqui cere-ere sinhetsi, obratu eta eskatu behar baita (Euscaldunei)

erraille : Meça-erraillea all]darera ethor dadinean, erraçu debotqui eta attentoqui othoitz haur. (194. o.)

eskale : Çure (...) ontasunean fidaturic heldu naiz eria midicua gana, probea aberatsa gana, escalea emaillea gana, biluça bestitçaillea gana, liçuna ura gana, eta itsua arguitçaillea gana. (248. o.)

langile : Cerbitçariey eta languiley bere soldataren eta iornalaren goratcea, eta bortchaz eduquitcea. (30. o.)

partale : (Iaincoak) egin gaitzala lehen baiño lehen bere ceruco erresumaco ontassun handi hetan partale (80. o.)

LE atzizkia bi oinarrirekin agertzen zaigu : alde batetik ondarrean $-n$ duten, edo $-i$ aspektu marka hartzen duten aditzoinei loturik, izen agentiboa eratuz : egile (EGIN), langile (LAN EGIN), erraile (ERRAN), emaile (EMAN), erakusle (ERAKUTS); beste aldetik, erabide berezia dutenak nolabait : begira(i)le, eskale, eta partale. Azken bien kasuan, LE da atzizkia (bustidurarik gabe) eta aktibitate izenak dira oinarrian : eske eta parte.

\section{MENDU}

adimendu : Eguiten derautcut othoitz ceure passione sainduaren merecimenduac gatic, nahi derautaçun neure espiritua arguitu, adimendua gobernatu, bihotça faboratu, eta orondatea (...) borthitztu (...). (245. o.)

bark(h)amendu : Baiña çuc emequi eta amoriozqui deithu nauçu ceure gana, eta cure ontasuna gatic barcamendu prometatu, (...). (228. о.)

deliberamendu : ... eguiten derautçut othoitz (...) nic orai eguiten dudan deliberamendu hunetan fermuqui irauteco eta perseueratceco. (245. o.)

desiramendu : Çu içanen çara hemendic aitcina ene desiramendu guztien gedea eta fina. (244. o.)

enganamendu: Khen itçaçu gure ganic espiritu gaixtoaren enganamenduac eta celatac (343. o.)

errepartimendu: Bada errepartimendu haur hunela ikussiric ditçagun declara Credo, Pater noster, Aue Maria, Salve Regina, Manamenduac, Sagaramenduac, eta bertce gaiñeraco (...) gauçac. (48.o.)

gidamendu : $\mathrm{Cu}$ (sic) çara emaçurţ̧ gaixoen aita, (...) Iustuen bozcarioa, eta errebelatuen guidamendua. (282. о.)

komplimendu : Ardiets diaçadaçu verthute guztien complimendua (290. o.) 
konsentimendu : Bekatu mortal da Iaincoaren eta gure Guiristino lagunaren contra eguiten den guztia, baldin gauça asco handia ba-da, eta borondatearen consentimendu ossoarequin eguiten ba-da. (165. о.)

konsolamendu : Eta othoitcez nagotçu odol preciau haren baliotasuna gatic, eta ordu hartan sentitu cenduen dolore handi hura gatic, eman nahi derautaçun mundu hunetaco gaitcen hain gogo onez pairatceco indarra, non tribucinoetan becela consolamenduetan ere partale guertha dadin. (202. o.)

kontentamendu : ... hetan eçar deçadan neure bihotça eta contentamendu guztia. (206. o.)

manamendu : Erran nahi du eman diaçagula garazia eta fabore haren manamendu sainduen beguiratceco (81. o.)

merezimendu : Eta !halacoec içanen dute merecimendu handia Iaincoaren aitcinenan, baldin bere promesa behar den bidean eduquitcen eta beguiratcen ba-dute. (149. o.)

mereximendu : Eta finean eman diaçaguçu çure semearen Passioneco mereximenduez ongui probetchatceco garacia. (222. o.)

pagamendu : Edirenen da segurqui handiago eta guehiago dela pagamendua çorra baiño. (218. o.)

pensamendu : Ezagutcen dut ecen çu çarela ene bicitçearen gobernaria, (...) eta pensamendu onen inspiratçailea. (293. o.)

sagaramendu : Edireiten dela Eliçan bekatuen eguiazco barkamendua Sagaramendu sainduen verthutez (72. о.)

sakramendu : Eta ceren çuc ceure Eliçan Penitenciazco sacramendua becatuen barcamendutan ordenatu baytuçu, ... (232. o.)

salbamendu : Ceren harequin eguin baitu Iaincoaren semeac gure salbamenduco obra $(410$.

sentimendu : Ene bihotz haur çaurt eçacu ceure amorioaren tragaçaz halaco moldez non dolorezco sentimenduz betheric ardiets deçadan çure ganic desiratcen dudan barcamendua. (236. o.)

tentamendu : Eta utzten gaituenean ere digula indar eta garacia tentamendu hequen garaitzeco (85. o.)

urrikalmendu(tsu) : A bihotz-bera, a urricalmendutsua, a maria virgina eztia. (6. o.)

urrikimendu : Lehenbicicoric behar dugu gure bekatuez bihotcezko urriquimendua, ez guehiago bihurtceco borondate fermuarequin. (134. o.)

MENDU atzizkiak maiztasun handia du Materreren lanean. Oinarria aditzoina da beti. $-t u$ aspektu marka dute edo $-i$ organikoa corpuseko aditz guziek, itxuren arabera morfologiari soilik behatuz ere edozein aditzek ez baitu MENDU atzizki hau onartzen. 
Sentimendu hitzaren kasuan duda izan daiteke ez ote den hitza mailegatua. Halere, horrelako maileguetan -mentu forma baliatzen zuen Materrek, hala nola iuramentu hitzean (eta horregatik azken hitz hau ez dugu eratorrien artean sartu).

Gisa horretan, komplimendu hitza, konpli aditzoinari dagokio beti Dotrina Christianan, 'konplitzea' adierazten duelarik.

Oin berekoak izanagatik, urrikalmendu eta urrikimendu formen arteko oposizioa garbia da, lehenbizikoa urrikal aditzoinari baitagokio eta bigarrena urriki aditzoinari. Urrikaldu aditza bera urrikari oinarritik eratorria da (urrikaritu dio Beriaynek 17. mendearen haste hartan, Sarasolak (1984-1995) dioenaz), eta norbait urriki ukaitea edo hartaz pietate ukaitea erran nahi du. Aldiz, urriki hitzak lapurteran zerbait gaizki egin ondoko dolua adierazten $\mathrm{du}^{(15)}$, eta urrikimendu hitza ere sentimendu berari doakio.

\section{OS}

guthizios : Pietateaz eguiten gara bihotz-bera, eta ongui eguitera guthi$\operatorname{cios}(153$. o.)

Guthizios hitzaren ondoan, beste batzuk badira -OS atzizkia dakartenak baina zerrendan sartu ez ditugunak zeren hitz osoa baitateke haien kasuan mailegatua : balios, bitorios, glorios, imbidios, miserikordios, perilos, superstizios. Guthizia oinarriaren euskal lexikotik ateraia da (bera ere, itxurak dioenaz, hitz mailegatua bada ere).

\section{PEN}

hats-beherapen : Cure gana gaude hatsbeherapenez, ayez, eta nigarrez. (6. o.)

erospen : Orhoit çaiteci ni çurea naicela creacinoz eta erospenez. (231. o.)

orhoitzapen : Meça saindua nola baita sacrificioa gure Salbatçailleac berac bere heriotçe eta Pasione Sainduaren orhoitçapenetan ordenatua, ... (188. o.)

PEN atzizkia aditzoinei bereziki lotzen zaie (behera, eros), batzuetan (T)ZA morfema ere agertzen delarik haren aitzinean oroitzapen hitzean bezala.

Hats-beherapen hitz elkartuaren kasuan, beherapen hitzaren oinarria behera aditzoina da, eta elkarketa bi izenen artean egiten da : $\left[\mathrm{HATS}_{\mathrm{I}}\right]\left[\left[\mathrm{BEHERA}_{\mathrm{A}}\right] \mathrm{PEN}_{\mathrm{I}}\right]$.

\section{RO}

xehero- ${ }^{(16)}$ :... pensa eçaçu (...) cer obra eguin duçun, geheroqui egiten duçula gogoeta cer becatu eguiten ahal duqueçun (313. o.) 
RO atzizki adberbialaren agerpen bakarra da. Ohargarria da KI atzizkia ere baliatua dela haren ondotik, RO-k bere balioa galdua zuelako marka, hain segur.

\section{(T)ASUN}

aberatstasun (17): Cer da Auaricia? Munduco aberatstasunen neurri gabeco guticia. (169. o.)

adiskidetasun : Eta eçarten gaitu Iaincoaren garacian eta adisquidetasunean. (135.)

amatasun : Cein da virgina Andre hunen laudorioric eta ohoreric handiena eta principalena? Amatassuna virginatassunarequin batean. (96. o.)

arartekotasun : Eta ceure arartecotassunaz ardiets diaçadaçu Iaincoa ganic (...) egun hunetan ibiltceco gracia. (186. o.)

baliotasun : Odol preciatu haren baliotasuna gatic (...) itça diaçadaçu, othoi, neure gorputça eta espiritua ceure beldurtassunaren itceaz. (204. о.).

batasun :... munduan dela eguiazco Eliça bat, erran nahi da, Guiristino fidelen biltçarre bat, compainia bat, eta battasun bat. (65. o.)

beldurtasun : Espiritu sainduaren dohaiñac dira çazpi. 1. cuhurcia. 2. Adimendua. 3. Conseillua. 4. Borthitztasuna. 5. Iaquintasuna. 6. Pietatea. 7. Iaincoaren Beldurtasuna. (284, o.)

berotasun : Cu çara emaçurtz gaixoen aita, hotcen berotasuna, necatuen pausatasuna, flacoen borthiztasuna. (282. о.)

biluzgorritasun : Betha eçaçu ene hutstasuna, estal eçaçu ene biluzgorritasuna, jahu eçaçu ene liçuntasuna, argui ę̧açu ene itsutasuna. (248. o.)

birginatasun : Cein da virgina Andre hunen laudorioric eta ohoreric handiena eta principalena? Amatassuna virginatassunarequin batean. (96. o.)

borthitztasun : Cu çara emaçurtz gaixoen aita, hotcen berotasuna, necatuen pausatasuna, flacoen borthiztasuna. (282. o.)

dohatsutasun : Cer aditcen duç dohatsunaren icenaz? Cembait obra verthutezcoac ceruco dohatsutasunaren ardiesteco bideac befala direnac. (155. о.)

emakhoitasun : Bekatu mortal buruçaguiac dira cazpi. 1. Urguillutasuna. 2. Auaricia. 3. Haraguizco bekatua edo emakhoitasuna. 4. Imbidia. 5. Gula edo sabeldarrayotasuna. 6. Hasserretassuna. 7. Naguitasuna. (26. o.)

emetasun : Cure ontasuna eta emetasuna narritatu dut neure gaixtaqueria handiez. (226. o.)

epeltasun : Bero çaçu ene epeltasuna (254. o.) 
eritasun : ... eraman nauçu becatutic garaciara, heriotcetic bicitcera, ilhumbetic arguitara, gathibutasunetic libertatera, eritasunetic ossasunera. (240. o.)

eskergabetasun : Accusatcen dut neure esquergabetasuna, ceren hain laxoqui eta ansicabequi utci dudan aita ona eta amoriozcoa. (226. o.)

etsaitasun: Halacoac [dohatsu] dira nehorequin etsaitcen eztirenac eta bertceren arteco gaitzerizcoac eta etsaitasunac iraunguiric (...) guztien adisquidetcera enseyatcen direnac. (166. o.)

eztitasun : Bethe eçaçu othoi ene arimaren apetitua ceure eztitasunaren çaporeaz. (263. o.)

fermutasun : Eta emaiten deraue etsai gaixto guztien contraco fermutassun handi bat; (128. o.)

flakotasun : Eta nola flacotasunezco bekatuac b-zitira Aitaren contra (...) hala maliçiazcoac dira Espiritu sainduaren contra. (173. o.)

gaixotasun : Eta nola Erregue Dauitec Misibeseth Ionathas bere adisquidearen seme gaixoa (...) bere mahayan errecibitu baiţuen, eta bere onetan eguin partale : hala ene gaixotasunari behatu gabe eguin naçaçu ni ere Sagaramendu Sainduaren mahay hunetan partale. (255. o.)

garbitasun : Ardiets diaçadaçu (...) arimaco eta gorputceco garbitasuna. (290. o.)

gathibutasun :... eraman nauçu becatutic garaciara, heriotcetic bicitcera, ilhumbetic arguitara, gathibutasunetic libertatera, eritasunetic ossasunera. (240. o.)

generaltasun : Eguiazco Eliça hunen eçagutceco markak eta seiñaleac cein dira eta cembat? Hirur : Batassuna, saindutassuna, eta generaltasuna. (67, o.)

giristinotasun: (Aditcen dut ...) nola guztiec baitute fede bat, legue bat, eta buruçagui bat, hala guztiec eguiten dutela Eliçabat eta guiristinotassun bat. (70. о.)

goratasun: Miresteco da eguiazqui nola f̧u Iainco gora eta maiestatezcoa çarelaric, ceure goratasuna hain beheitituric nahi içatu duçu ene arimaren etchean sarthu. (259. о.)

haserretasun: Bekatu mortal buruçaguiac dira çazpi. 1. Urguillutasuna. 2. Auaricia. 3. Haraguizco bekatua edo emakhoitasuna 4. Imbidia. 5. Gula edo sabeldarrayotasuna. 6. Hasserretassuna. 7. Naguitasuna. (26. o.)

handirasun: Halacoac [dohatsu] dira munduco onhassunac eta handirasunac Iaincoa gatic vzten dituztenac. (156. o.)

handitasun : Argui eçaçu bada othoy ene espiritua eta memoria ceruticaco arguiaz, harlaco moldez non neure becatuen itsusitasuna, handitasuna eta pisutasuna ę̧aguturic, cofessa ditçadan librequi, clarqui, eta bidezqui. (233. o.) 
hiltasun : Cer da Naguitasuna? Gogoaren hiltasun bat ceinetçaz eguiten baita presuna hain triste eta pisu, non ... (171. o.)

hotztasun : Eta ene bihotçaren hotztasuna bero eçaçu çeure suaren carraz. (283. o.)

humiltasun : Çazpi bekatu hauquen contra badira çazpi erremedio. 1 . Vurguillutasunaren contra, humiltasuna. 2. Auariciaren contra, liberaltasuna. (27. .)

hutstasun: Betha eçaçu ene hutstasuna, estal eçaçu ene biluzgorritasuna, jahu eçaçu ene liçuntasuna, argui ę̧açu ene itsutasuna. (248. o.)

iainkotasun: (Aditcen dut) Iaincoa baithan eztela edireiten Iaincotassun bat, içaite bat, eta naturaleça bat baicen. (39. o.)

iakintasun : Iaquintasunaz ikasten dugu cer den Iaincoaren borondatea. (i53. o.)

ilhuntasun : Ene barreneco ilhuntasunac arguitçaçu ceure claritateaz. (283. o.)

indignetasun : Eçagutcen dut neure indignetasuna. (252. о.)

itsusitasun : Argui eçaçu bada othoy ene espiritua eta memoria ceruticaco arguiaz, harlaco moldez non neure becatuen itsusitasuna, handitasuna eta pisutasuna eçaguturic, cofessa ditçadan librequi, clarqui, eta bidezqui. (233. о.)

itsutasun: Betha eçaçu ene hutstasuna, estal eçaçu ene biluzgorritasuna, jahu eçaçu ene liçuntasuna, argui eçaçu ene itsutasuna. (248. o.)

liberaltasun : çazpi bekatu hauquen contra badira çazpi erremedio. 1. Vurguillutasunaren contra, humiltasuna. 2. Auariciaren contra, liberaltasuna. (27.)

lizuntasun : betha eçaçu ene hutstasuna, estal eçaçu ene biluzgorritasuna, jahu eçaçu ene liçuntasuna, argui eçaçu ene itsutasuna. (248. o.)

nagitasun : Bekatu mortal buruçaguiac dira çazpi. 1. Urguillutasuna. 2. Auaricia. 3. Haraguizco bekatua edo emakhoitasuna 4. Imbidia. 5. Gula edo sabeldarrayotasuna. 6. Hasserretassuna. 7. Naguitasuna. (26. o.)

onhasun: Cer deitcen duçu borondatezco probetasuna? Munduco onhasun guztiac Iaincoa gatic utciric bere bereric ez deus eduquitcea. (146. о.)

ontasun : Ontassunez denaz beçanbatean, lehenbicico galdeguiten dugun ontassuna da ohora eta lauda dadin Iaincoa (88. o.)

osasun : Finean gorputceco ossasuna emaiten deraue, baldin arimacotçat behar badute (136.)

partaletasun : Eta eguin naçaçu ceure gorputz preciatuaren partaletassunaz behar den gauça guztietaco gay eta digne. (254. o.) 
pausatasun : Cu çara emaçurtz gaixoen aita, hotcen berotasuna, necatuen pausatasuna, flacoen borthiztasuna. (282. о.)

pisutasun : Argui eçaçu bada othoy ene espiritua eta memoria ceruticaco arguiaz, harlaco moldez non neure becatuen itsusitasuna, handitasuna eta pisutasuna eçaguturic, cofessa ditçadan librequi, clarqui, eta bidezqui. (233. o.)

probetasun : Cer deitcen duçu borondatezco probetasuna? Munduco onhasun guztiac Iaincoa gatic utciric bere bereric ez deus eduquitcea. (146. o.)

sabeldarraiotasun : Bekatu mortal buruçaguiac dira çazpi. 1. Urguillutasuna. 2. Auaricia. 3. Haraguizco bekatua edo emakhoitasuna 4. Imbidia. 5. Gula edo sabeldarrayotasuna. 6. Hasserretassuna. 7. Naguitasuna. (26. o.)

saindutasun : Eguiazco Eliça hunen eçagutceco markak eta seiñaleac cein dira eta cembat? Hirur : Batassuna, saindutassuna, eta generaltasuna.

urguilutasun : Cer da urguillutasuna? Sobera abantail bere burüari desiratcea, eta bertceac mesprejaturic nehor bere berdin ez eduquitcea. (168. o.)

TASUN atzizkia da corpusean hitz gehieni bidea irekitzen diona. Izen kategoria emaiten dio eratorriari eta oinarria izena edo izenondoa da, salbuespenik gabe (hiltasun eta jakintasun hitzen kasuan hil eta jakin izenondotzat hartzeko dira orduan).

Onhasun eta ontasun hitz eratorriak oposatzen ditu Materrek, zenbaitetan hitz jokoak ere eginez: Utci çaitut ene ontasun guztia çarena, lurreco onhasun ez-teusei itchiquitceagatic (226. o.). Ontasun balore morala da gehienetan Dotrina Christiana liburuan, eta onhasun, aldiz, aberastasun materialen izendatzeko erabilia da (salbuespenik gabe, bat edo beste itzuri ez bazait). Axularrek ere, modu bereko bereizkuntza egiten zuen.

Handitasun / handirasun dobletea ere aurkitzen da: handitasun termino markatugabe gisa agertzen da, handirasun bereziki gizarteko ospakizunei edo jendeen ospeari dagokielarik. Bikoiztasun hori Leizarragaren lanetan ere aurkitzen da, bai eta Axularren obran ere. ${ }^{(18)}$

\section{TI}

egiati : Educaçu nitçaz contu, hala nola redemitu bainauçu, Iainco eguiati çarena (323. o.)

TI atzizki adjektibalaren agerpen bakarra, egia izena oinarri delarik. Leizarragak ere enplegatzen zuen hitz eratorri honen erabilera ahulduz joan da azken mendeetan, gizaldi honetan kasik batere ez baita agertzen, iparraldean segurik (OEH, egiati sarrera). 


\section{TO}

gaixto: Deliberatcen dut neure bicitce gaixtoaren utztera. (229. o.)

liburutto: Hartu dut gogo liburutto hunen eguiteco, eta iendartera atheratceco (Euskaldunei)

TO atzizkiak balio tipiagotzailea du gutiz gehienetan eta hala da adibidez corpusean libutto hitzean, kontestu horretan estonagarri ez den sabaikaritze batekin (-TTO). Ordean, gaixto hitzaren kasuan, iduri luke atzizki berak kontrako balioa hartu duela (cf. Ühlenbeck 1909). Atzizki handi- edo tipiagotzaileek ez ohi dute oinarriaren kategoria kanbiatzen.

TSU

botheretsu : Iainco Iauna guciz botheretsua, ... (182. o.)

dohatsu- : Cer aditcen dicu dohatsunaren icenaz? Cembait obra verthutezcoac ceruco dohatsutasunaren ardiesteco bideac beçala direnac. (155. o.)

egartsu : Eta badaquit nehorc-ere (...) ecin iraungui deçaqueyela ene egartsu handiaren sua. (250. o.)

iakintsun : Erran nahi da dela (...) Iainco eguizco, haste eta fin gabe, guztiz botheretsu, guztiz on, guztiz iaquitsun, gau[c] g guztien Creatçaille eta Iaun. (64. o.)

urrikalmendutsu: A bihotz-bera, a urricalmendutsua, a maria virgina eztia. (6. o.)

TSU atzizki adjektibala lau aldiz agertzen da corpusean, hitzoina izena izanik : bothere, egarri, urrikalmendu. Dohatsu forma ere agertzen da dohatsutasun hitzaren barnean. Oinarria kasu horretan *doha forma dugu, modu horretan behintzat euskaran agertzen ez dena (ikus halere, inguruko eremu semantiko batean, erro bereko bi hitz : mendebaldean doe, eta ekialdean dohain).

Eratorriaren kategoriaren aldetik, egartsu salbuespena da gure corpusean, argi eta garbi izena baita hitza, ez izenondoa. Axularrek ere horrela erabili zuen hitz hori, bai eta 19. mendea arte beste lapurtar klasikoek.

Jakintsun hitza berezia da : alde batetik TSUN baita atzizkia hartan ; beste aldetik, oinarria aditz partizipioa baita, izenondo gisa usaian balio aktiborik ez duena (ezezkoan errazkiago, halere : Guziz gizon ezjakina da vs ??Guziz gizon jakina da).

Lehen ponduari buruz, erran daiteke sudurkariaren aitzinerako hedamen baten ondorioz agertu dela TSUN forma (Michelena, 1960), hegoaldean jakintsu forma nagusitzen zelarik.

Bigarren ponduari buruz, derragun jakintsu(n) ez dela adibide bakarra mota horretakoa ; adibidez, ukansuago forma agertzen da Leizarragaren itzulpenetan (San Paulok korintiarrei egin 1. gutuna), ukhan aditza izanik oinarria, eta balio aktiboa izanik hitz eratorriak (oinarriak berak, bizkitartean, nekez izan dezakeelarik). 


\section{TZA}

ezagutza: Iduritçen çait hoben nuqueyela, eta ere ę̧agutça gutitaco eta esquer gabe içanen ninţ̧ela, ... (Euskaldunei)

ezkontza : Seigarrena [manamendua] : haraguizco obraric ezcontçaz campoan eztaguigula. (8. o.)

TZA atzizkia bi aldiz baizik ez da agertzen. Oinarria aditzoina da eta aditz horri dagokion izen da hitz eratorria.

\section{TZA(I)LE :}

argitzaile : Çure (...) ontasunean fidaturic heldu naiz eria midicua gana, probea aberatsa gana, escalea emaillea gana, biluça bestitçaillea gana, liçuna ura gana, eta itsua arguitçaillea gana. (248. o.)

arintzaile : Becatuz cargatua ba-naiz, çu çara arintçailea eta barcatçailea. (277. o.)

bark(h)satzaille : Becatuz cargatua ba-naiz, çu çara arinţ̧ailea eta barcatçailea. (277. o.)

bestitzaille : Çure (...) ontasunean fidaturic heldu naiz eria midicua gana, probea aberatsa gana, escalea emaillea gana, biluça bestiţ̧aillea gana, liçuna ura gana, eta itsua arguitçaillea gana. (248. o.)

edukitzaille : Eta battassun hartan bici direla guztiac buruçagui baten gobernuaren azpian, cein baita Erromaco Aita saindua, lurrean Iaincoaren lekuaren eduquitçaillea, et haren eguiazco Bicarioa. (68. o.)

examinazale : Examinaçaleen approbacinoa.

faboratzaille : Ecen çu çarela ene bicitçearen gobernaria (...) adimenduaren arguitçailea, beharretan faboratçaillea, periletan beguiraillea, arduraco ongui eguilea, eta pensamendu onen inspiratçaillea. (293. o.)

garbitzaille : Çu çara bihotcen arguitçailea, tristeen consolatçailea, iaquin-gabec (sic) iracatsaillea, erien sendatçaillea, liçunen garbitçaillea, eta dohain guzien emailea. (282. o.)

imprimatzaille : Iacques Millanges Erregueren Imprimaçailearenean. (Estalgiko 1. o.)

inspiratzaille : Ecen çu çarela ene bicitçearen gobernaria (...) adimenduaren arguitçailea, beharretan faboratçaillea, periletan beguiraillea, arduraco ongui eguilea, eta pensamendu onen inspiratçaillea. (293. o.)

irakatsaille : Çu çara bihotcen arguitçailea, tristeen consolatçailea, iaquin-gabec (sic) iracatsaillea, erien sendatçaillea, liçunen garbitçaillea, eta dohain guzien emailea. (282. o.)

irakurzaille $^{(19)}$ : Iracurçailleari. 
iratzarzaille : Halatan iratçarçaille, orhoitçaille, eta eguiazco Sainduen representatçaille beçala ohoratcen eta adoratcen ditugu imaginac. (105. o.)

konsolatzaile : Çu çara bihotcen arguitçailea, tristeen consolatçailea, iaquin-gabec (sic) iracatsaillea, erien sendaţ̧aillea, liçunen garbitçailllea, eta dohain guzien emailea. (282. o.)

kreatzaille : eta aitortcen dut çu çarela ene Creatçaillea, (...) ontassun guztien ithurria, eta bai emaillea ere. (183. o.)

lorifikatzaille : çazpigarrena [manamendua], iaincoa dela lorificatçaillea. (13. o.)

maitatzaille : Ha! guiçonen maitatçaille handia, (...) othoitçez nagotçu ... (251. o.)

orhoitzaille : Halatan iratçarçaille, orhoitçaille, eta eguiazco Sainduen representatçaille beçala ohoratcen eta adoratcen ditugu imaginac. (105. o.)

representatzaille : halatan iratçarçaille, orhoitçaille, eta eguiazco Sainduen representatçaille beçala ohoratcen eta adoratcen ditugu imaginac. (105. o.)

sakrifikatzaille : Haur da Sacrificatçaille eternala, baquezco sacrificioa Caluarioco mendian offerendatu derautçuna. (213. о.)

salbatzaille : Cergatic deitcen da Salbatçaille? Ceren bere Passione sainduaren verthutez etsai gaixtoaren botheretic (...) salbatu eta athera baicaitu. (97. о.)

Salbuespenak salbuespen, TZAILE atzizki agentiboa LE atzizkiarekin banaketa konplementarioan da, oinarriaren formaren arabera. TZAILE, - $t u$ aspektu marka duten edo $i$ organikoa duten aditzei dagokie. Halere kasu batean bederen ez da betetzen bereizketa hau gure corpusean : irakats(i) aditzari dagokion iracatsaille forman hain zuzen. Iratçarçaille hitzaren kasua ere aipa daiteke, baina kontua ez da hain garbi azken honetan. Alabaina, iratzar(tu) aditza ere ezaguna da, iratzarri forma adjektibalaren ondoan. Are gehiago Orotariko Euskal Hiztegiak kausatiborik gabeko aditzaz dioenaren arabera (ik. atzarri sarrera), Lapurdiko autore zaharretan (18. mendea baino lehenagoetan) atzartu forma zen aditz jokaduran enplegatzen zena, atzarri forma adjektibal gisa agertuz bakarrik. Pentsa daiteke gauza bera zela forma kausatiboarentzat, eta molde horretan iratzartzaile forma guziz erregularra da.

Irakatsaille hitzaren kasua bestelakoa da. $(t) s+(t) z$ elkartzearen ondorioa ts da euskaraz (Michelena 1960, 350. o.), eta irakatsaile forma irakats $+(t)$ zaile erabidearen ondorio gisa aztertzekoa da. Gisa horretan, igurikatzen ez dugun erabidea dugu, *irakastu forma ez baita ezaguna. Autore zaharretan iracatsle dio Leizarragak eta hori da nagusi izan den forma. Irakastaile forma ere eskaintzen du, halere, Lhandek Harrieten eskuizkribuari erreferentzia eginez; irakatsaile formaren bariante gisa hartzeko bide da azken forma hau. 
Ohartzekoa da atzizkia beti TZAILE dela /1/ fonema sabaikariarekin hain segur, eta aitzineko xistukaria afrikatua izanik. Materrek morfemaren afrikazioa ez du ortografiatzen, haatik, r-en ondotik (iracurçaille, iratçarçaille).

ZALE forma Dotrinan ere agertzen da, baina liburuetako hatsarreko orrialdeetan, ez baitu iduri Materrek berak idatzia zuela (examinaçaleen approbacinoa). Beste kasu bat ere bada (nekhazale), baina ez da segur atzizki agentiboa den azken hau (ik. beherago ZALE atzizkia).

Beste hitz bat bada bereziki seinalatzekoa dena corpusean, ez formagatik baina erabileragatik. Sakrifikatzaile hitza da. Alabaina, hitz hori adibidean erabilia den bezala, sakrifika aditzoina erreflexiboki (eta segurenaz ere iragangaizki) interpretatu behar da, eta ez aditz iragankor arrunt gisa.

\section{TZE}

heriotze : ... eraman nauçu becatutic garaciara, heriotcetic bicitcera, ithumbetic arguitara, gathibutasunetic libertatera, eritasunetic ossasunera. (240. о.)

TZE atzizkia izen adizki bati zegokionetan ez dugu kontuan hartu. Bestelakoetan, heriotze da kasu bakarra, izena izanik oinarrian.

\section{ZALE}

nekhazale : Eztugula halaber (...) nekazaleen edo cerbitçarien iomalic edo soldataric ere goraturic eta bortchaturic eduqui. (115. o.)

ZALE atzizkia agertzen den adibide bakarra nekhazale hitza da. Nola atzizki agentiboarentzat TZAILLE erabiltzen baitu beti Materrek (testutik kanpo agertzen den examinazale hitza kontuan hartzen ez bada), hemen beste atzizki bat dukegu, eta ez atzizki agentiboa. Axularrek ere TZAILE erabiltzen du beti atzizki agentiboarentzat, ZALE atzizkia bi hitzetan baizik ez erabiliz: arran(t)zale eta nekhazale, eta beraz bereizkuntza garbia eginik hark ere. Horiek horrela, bi atzizkiek forma bera (ZALE) dute ekialdeko euskalkietan, eta hala zen Leizarragaren idazkietan ere.

\section{ZARRE}

biltzarre : Sinhetsi behar dugula munduan dela eguizco Eliça bat, erran nahi da, guiristino fidelen biltçarre bat, compania bat eta battassun bat. (65. o.)

ZARRE atzizkia aditzoinei lotzen zaie, eta hauei dagokien ekintza izen gisa adierazten du. Biltzarre adibide bakarra da corpusean.

\section{ZIA}

ausartzia : ... eta emaiten deraue etsai gaixto guztien contraco fermutassun handi bat, eta are (...) Iancoa gatic biciaren (beharba-da) emaiteco esportua eta ausartcia. (119. o.) 
tristezia : Othoitçez nagotçu (...) çuc orduan sentitu cenduen tristecia handi hura gatic (197. o.)

zuhurzia : Prudenciac edo cuhurciac eracusten deraucu nola gobernatu behar garen gure eguitecoetan. (144. o.)

ZIA erromanotik hartu atzizkia da, corpusean hitz mailegatu batzuetan kausitzen duguna (temperancia, malicia, prudencia, obediencia, ...). Halere euskarak beretu baitu atzizki hau euskal oinarriekin ere agertzen da hala nola zuhur eta ausart izenondoekin gure corpusean. Kasu batzuetan neke da jakitea forma osoki mailegatua den ala, oinarrian den izenondoa ere beretu baitu euskarak, euskal eratorri gisa kontsidera daitekeen, tristezia hitzaren kasuan bezala. gun.

Bilketa honen ondoan, zenbait ohar orokor laburzki egin ditza-

Lehenik azpimarratzekoa da Materrek ez dakarrela euskararen morfologia kolpatzen duen hitz berririk, eta alderdi horretarik osoki fidatzekoa dela haren idazlana.

Ez dugu erran nahi horrekin ez dela hitz bat edo beste, euskal literaturan Materreren lanetan baizik agertzen ez denik, eta beharbada berak bere buruz enplegatu zuenik. Adibidez agertuki edo desiramendu hitzak ${ }^{(20)}$ Materreren erreferentzia xoilarekin agertzen dira Orotariko Euskal Hiztegian. Haatik, ez da dudarik euskal gramatika zaurtu gabe eratuak direla hitz horiek, eta irakurtzaile arruntek zailtasunik eta bortxarik gabe konprenitzeko modukoak.

Orohar, modu neurtuan baliatzen da erator atzizkiez Materre. Orotara, adizkiak kontuan hartu gabe, 181 hitz eratorri desberdin zenbatu ditugu haren lanean, 28 atzizkiri esker sortuak.

Atzizki emankorrena (T)ASUN (53 hitz), eta KI adberbiala (37 hitz), dira. Ondotik, MENDU ( 23 hitz) eta atzizki agentiboak ditugu : TZAILE (21 hitz) eta LE ( 8 hitz). Gero TSU ( 5 hitz), ARI-1 (3 edo 4 hitz) eta PEN (3 hitz) ditugu. 


\section{NOTES}

1. Lakarrak $(1994,55$. o.) adibide ezin adiererazgarriagoa eskaintzen du horretaz. Harrieten gramatikako hiztegia (1741) azterkaturik ohartarazten du euskarazko sarrera duen hiztegian hitz bat baizik ez dela KUNTZA atzizkia duenik (hitzcunça) ; aldiz frantsesezko sarrerei dagozkien euskal hitzetan 41 hitz dira, KUNTZA atzizkia dakartenak.

2. L'horloge spirituelle des âmes dévotes et religieuses consacrées au service de Dieu, chez Sevestre à Paris. cf. Vinson (1891 \& 1898).

3. Sorginkeriazko auzien ondotik bazterren jabaltzera eta jendeen argitzera etorria ote zen Materre? Menturaz, bai. Veyrinek (1943) dioenaz, urte haietan (1611an) eraiki zuten Frantziskanoek Donibane Lohizunen eta Zibururen artean komentu bat Lapurdiko nahasmenduen eta izigarrikerien ondotik bakearen ekartzeko. Edozein modutan ere ohargarria da Materreren dotrina horretan badirela sorginkeriaz solas batzuk, orduan Lapurdin iragan berri ziren gertakariak hitz erdizka bederen gogora dakartzatenak : Sorguinac dira iende thaillu batçuc ceiñec (diotenez) arnegatcen baitute bere eguiazco Iaincoaz, fedeaz, legueaz, errecibitu duten bathayoaz, Aitamaz, eta Eliçaco gauça guztiez eta guero hancen dute bere iaun eta nabussi deabrua, adoratcen dute, cerbitcacen dute, eta haren borondatearen arauaz (bera laguntcen çayela) eguiten dute ahal daguiten gaizqui guztia, guztiz-ere haurretan, eta lurreco fruitutean, eta halatan hec dira munduan diren ienderic gaixtoenac, Iaincoz eta munduz erratcea mereci dutenac. (106-107. o.).

Ene jakinean, Lapurdiko 17. mendeko euskarazko idazlanetan testu bakarra da sorginkeriazko auziak hitz laburretan eta aski orokorki bada ere, aipatzen dituena. Axularrek berak ere gai hori ez zuen hunki.

4. Vinsonek (1891) duda agertzen du ea Materreren liburua Baile jesuistaren katiximaren itzulpena ez ote den. Horrelako idazlanek berezkorik guti ohi dute, baina apezpikuari eskaintzen dion hitzean garbiki dio Materrek Euskal Herrian euskaldunentzat pentsatua eta egina izan dela liburua : Voicy ce livret escrit en Basque \& dressé pour le profit des Basques (...) Il vous est iustement deu, puis qu'il a esté conţu dans le territoire de votre dioceze.

5. Duen interesagatik, eta Materreren liburua eskuragaitz izanik, hona hemen azalpen horietako parte bat : Miretsico duçue aguian (Euscal-herrico ez naicelaric) Euscaraz esquiribatceco ausartçiaren hartcea. Baiña baldin considera ba-dadi edirenen duçue eztela gauça hunetan ausartciaric, eta ez cer miretsiric : aitcitic bertcela eguin ba-nu miretsi behar f̧atequeyela eta erran ahanci citçaitala neure eguinbidea. Ceren Iaincoac niri hitzcunça hunen ikasteco ence appur bat eman derautanaz gueroz, iduritcen f̧ait hoben nuqueyela, eta ere eçagutça gutitaco eta esquer gabe içanen nintcela, baldin Euscal-herrian ikassia Euscalherrico probetchutan emplegatu ez-panu.

Euangelioco cerbiţ̧ari alfer hura gaztigatu çuen bere nabusiac, ceren irabacian erabiltceco errecibitu çuen talentua eta dirua estalia eta ehorcia eduqui çuen. Handic içan naiz ni ere beldur hala guertha cequidan, baldin Euscaraz minfatceco ardietsi dudan talentua eta iaquina arima irabacian emplegatu gabe ehortcia eta gordean eduquitcen ba-nuen.

6. Idazlan honetan Dotrina Christiana-tik atera aipuetan agertzen diren azpimarrak eneak dira beti [B.0.].

7. Oxford-eko bibliotekan dagoen $1623 \mathrm{ko}$ argitalpenaren ale baten fotokopia erabili dugu guhaurk lan honen egiteko. Kopian berean errana denaren arabera zenbait orrialde falta baitziren liburuan (258-261 bitartekoak), 1704eko argitalpeneko ale batetik hartua izan da eskas zen testua.

8. Zuberoan Belapeyrek erabili bide zuen Materreren lana. Adibidez, ohar gaitezke sorginkeriaz Materrek erranak (ik. gorago 3. oharra) berriz aurkituko direla lauetan hogei urteren buruan Belapeyreren katiximan (1696), euskalki egokitzapenez landa kasik deus aldakuntzarik gabe :

- Beelhagiliac (sic) cer gente dira eta nola houx eguiten die lehen maniaren contre? 
- Gente eta espiritu apal elibat, fognec dioyenaz arnegatcen baitie bere eguiazco Gincoa, eta batheyu santian hartu dien fedia eta Jesus-Christen leguia; Aita ama, eta Eliçaco gaifa guciac: Eta guero hartcen die bere Jaun eta burçagui Deebria, adoratcen die, cerbutchatcen, eta harc nahi beçala, bera laguntcen çayela, eguiten dutie gaizki ahalac oro, guciz haurretan, aberetan, eta lurreco frutietan; halatan munduco gente gaistoenac dira Gincoaz eta legue oroz erre merechi dienac.

Zer erran nahi ote du horrek? Bi idazleek pasarte hori beste nonbaitetik hartu ote zuten eta euskarara itzuli ? Nekez, ene ustez, hain elkarren iduriko itzulpenak egin zitezkeen batak bestearen lana ikusi gabe, eta segurenaz ere Belapeyre Materreri jarraiki zitzaion lehen manamenduaz aritzeko. P. Agirrek (bidean) egiaztatu duenaren arabera (k. p.) beste pasarte batzuetan ere jokabide horren hatza kausi daiteke Belapeyreren katiximan.

9. Axularrek ere ideia bertsua garatu zuen euskaldunei eskaini aitzin hitzetan : Baiña zeren komunzki, hala eskiribatzea, nola minzatzea, nori berea iduritzen baitzaika hoberenik eta ederrenik : eta ene haur ezpaita zurea bezala, ez, ot hoi, hargatik arbuia eta ez gaitz erran. Hunetzaz kontent ezpazara, egizu zuk zeure moldera, eta zure herrian usatzen eta segitzen den bezala. Zeren ez naiz ni hargatik bekhaiztuko, eta ez mutturturik gaitzez iariko.

10. Egia erran, adiztasunaren seinalatzeko ere erabiltzen da maiz - $t u$ marka (aditzen izendatzeko adibidez, hegoaldeko tradizioan), eta badirudi gramatikariek horrela baliatu izan dutela gehienik deribazioaren aurkezterakoan. Nolanahi ere aditz bat eratorketaren bidez sortzen denean, eta eratorketa berri baten oinarri izaiten denean, ez ohi da hartan erator atzizki berezirik agertzen (edo $-\varnothing \mathrm{da}$ ). Adibidez berogailu aditzaren deskribaketa morfologikoa honela litzateke : [[[ $\left[\right.$ bero $\left.\left._{1-0}\right] \varnothing_{A}\right]$ gailu $\left.]_{1}\right]$.

11. Trask-ek (1985) IZENA + IZENONDOA + KO formak eratorriak direla dio, zeren oinarria izen multzo soila den eta erregulartasunik gabeko erabidea ere den. Halere, morfofonologia kontuan hartuz gero : $e$ - loturazkoa KO izenondoari lotzean (beso laburr-e$k o$ ), eta zenbait euskalkitako -TAKO formak (fede xipitako, indar xipitako, etab... Leizarragaren eta Lapurdiko eta ekialdeko beste askoren lanetan, eztabaigagarri iduritzen zait azterketa hau, ezen kasu markadurako morfofonologia lexikoan sartzera behartzen baikaitu.

Bestalde, KO-rekin segituz, baina aitzineko kontutik desberdina den buruhauste batera iraganez, ez da dudarik izen anitz ditugula euskaraz KO atzizkia dakartenak. Mota horretako izenak oinarri askotakoak izanarren beti ere izenlagun bat dute oinarrian eta izenlagunari dagokion izen ardatzaren isiltzetik (ez KO atzizkitik beretik) sortu da izen erabilera, gero gisa horretan lexikalizatu dena : aireko, ararteko, bateko, belarrondoko, etxeko, lekuko, oinetako, ...

\section{Alegera (izenondoa) / alegriantza (izena) bikotea Axularren idazkian ere agertzen da.}

13. Besarka izenaz eman diren beste azterkabideentzat ikus Agud \& Tovar (1989 - , besarka sarrera). Michelenak (1968) seinalatzen duen bezala eskuarki ere modu berean azter daiteke : ESKU+(H)AR+KI (cf. fr. maintenant).

14. Materreren grafia aldakorra da [kh] soinuaren idazterakoan : batzuetan $\mathrm{KH}$ idazten $\mathrm{du}$, besteetan $\mathrm{K}$. Ordean, $\mathrm{C}(\mathrm{A})$ / QU(I) grafiaz baliatzen da beti herskaria aspiratua ez denean. Barkiha aditzoinaren grafia, berriz, ez du beti berdin ortografiatzen : barca / barka I barkha, eta horregatik aspirazioaren zeinua parentesien artean utzi dugu transkripzioan.

15. Vrriqui hitza dolu itzuli zuen Leizarragak Zuberotarrentzat egin bere hiztegi laburrean.

16. Materrek $G(E)$ eta $J(A)$ letraz baliatzen da xixtukari sabaikariaren (gaurko X) idazteko : gehero, jahu, ijilik, etab... Axularrek grafia horren berri eman zuen bere liburuko aitzin solasean buruhauste ortografikoak aipatzean.

17. Aberats hitzoinean TS atzizki eratorlea ez ote den galdatua izan da literaturan (ik. bereziki Ûhlenbeck 1909). Ez dugu halere atzizki hau kontuan hartu, gauzak ez baitira biziki garbi eta, nolanahi ere, atzizki hipotetiko horren hedadura franko mugatua delakotz. 
18. Bekatuez mintzatzerakoan, handitasuna zioen Leizarragak (Materrek bezala), ez handirasuna. Ordean handiki baten ahalmenaz-edo aritzeko bai handirasun, bai handitasun erabiltzen zituen. Horrela, bere katiximan Erregeri egiten dion hitzean handirasun enplegatzen du puissança hitzaren ondoan : Hambatequin, hari berari othoitz eguiten draucagu Iauna, cure adinarequin çure handirassuna eta puissançá emendatuz, çure etsay ororen gainean victoria emanez, eguimbide eta iustitia orotan bethi çure Maiestatearen thronoa confirmatuz, bere Spirituaz ardura goberna eta guida çaitzala.

Urrunago, berriz, galde-erantzunetan handitasun erabiltzen du bothere hitzarekin batean : orduan Iaincoa exaltaturen da, eta creatura gucia haren botherearen eta handitassunaren menera humiliaturen : eta bera if̧anen da gucia gaufa gucietan.

19. Letra larrietan idatzia da hitz hori, eta $C$ letra agertzen da liburuan, batere dudarik gabe inprimategian ç grafia ez baitzitekeen letra larritan eman. Gauza bera gertatzen da EXAMINACALE hitzean, letra larrietan horrela idatzia eta examinaçale irakurtu duguna.

20. Orotariko Euskal Hiztegiaren arabera desirmendu hitza eskaintzen du Pouvreauk bere hiztegian. Azken hau hutsa ez bada, ez da dudarik desiramendu hitza hurbilagotik jarraikitzen zaiola euskararen morfologiari bestea baino, MENDU atzizkia aditzoinei lotzen ohi baitzaie : desira hala da; ez, ordean, desir.

21. Frantsesezko itzulpenarekin batean, hitzaren ondotik erator atzizkia parentesien artean emaiten dugu, irakurtzaileak artikuluan non bila jakin ahal dezan. Kontuan har bedi, artikuluaren hastapenean adierazia den bezala, adizkiei dagozkien formak (bestela lexikalizatu direnean ere) ez direla zerrendan bildu. Bistan dena, itzulpena Materreren erabilerari dagokio. 


\section{Eranskina}

Adizkiez kanpoko hitz eratorriak Materreren Dotrina Christianan. (21)

abantaillatuki (KI -1) avantageusement aberatstasun (TASUN) richesse adimendu (MENDU) entendement adiskidetasun ( (T)ASUN) amitié agertuki (KI -1) à découvert ahalkegabeki (KI -1) effrontément, impudemment alegriantza (ANTZA) joie, allégresse amatasun ((T)ASUN) maternité ansigabeki (KI -1) insouciamment arartekotasun ((T)ASUN) médiation argitzaile (TZAILE) qui éclaire arintzaile (TZAILE) qui allège atentoki (KI -1) attentivement ausartzia (ZIA) audace baliotasun ((T)ASUN) valeur banoki (KI -1) vainement bark(h)akizun ((K)IZUN) véniel, aisément pardonnable bark(h)amendu (MENDU) pardon bark(h)atzaille (TZAILE) qui pardonne batasun ((T)ASUN) union begira(i)le (LE) protecteur, gardien beldurtasun ((T)ASUN) crainte beregainki (KI -1) spécialement bereziki (KI -1) spécialement berotasun ((T)ASUN) chaleur besarka (KA) embrassade bestitzaille (TZAILE) qui habille bidezki (KI -1) dûment, comme il se doit biltzarre (ZARRE) assemblée biluzgorritasun ((T)ASUN) nudité birginatasun ((T)ASUN) virginité borthitztasun ((T)ASUN) force borthizki (KI -1) fortement, violemment botheretsu (TSU) puissant debotki (KI -1) dévotement deliberamendu (MENDU) décision desiramendu (MENDU) désir desoneski (KI -1) malhonnêtement digneki (KI -1) dignement dohatsutasun (TSU+(T)ASUN) béatitude edari (ARI 2) boisson edukitzaille (TZAILE) qui tient, détient egartsu (TSU) soif egiati (TI) sincère 


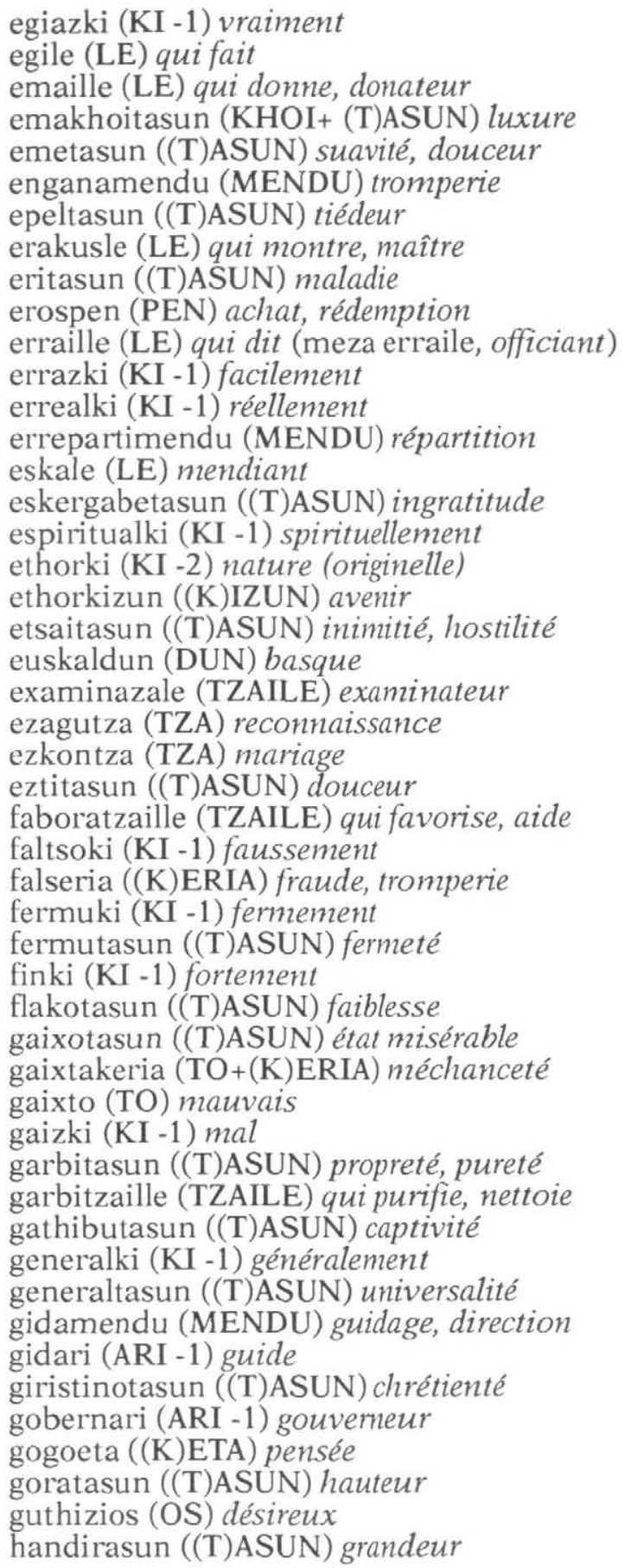


handitasun ((T)ASUN) grandeur haserretasun ((T)ASUN) colère hats-beherapen (PEN) soupir heriotze (TZE) mort herstura (DURA) détresse hilgarri (GARRI) mortel (actif) hiltasun ((T)ASUN) torpeur, apathie hitzkuntza (KUNTZA) langue hobekiago (KI -1) mieux (adverbial) hotztasun ((T)ASUN) froideur humilki (KI -1) humblement humiltasun ((T)ASUN) humilité hutstasun ((T)ASUN) vacuité iainkotasun ((T)ASUN) divinité iaki (KI -2) nourriture

iakintasun ((T)ASUN) savoir, science iakintsun ((T)ASUN) savant ilhuntasun ((T)ASUN) obscurité imprimatzaille (TZAILE) imprimeur indignetasun ((T)ASUN) indignité inspiratzaille (TZAILE) inspirateur irakatsaille (TZAILE) enseignant irakurzaille (TZAILE) lecteur iratzarzaille (TZAILE) qui réveille itsusitasun ((T)ASUN) laideur itsutasun ((T)ASUN) aveuglement izialdura (DURA) frayeur klarki (KI -1) clairement

komplimendu (MENDU) complétude, accomplissement komplituki (KI -1) intégralement, de façon complète ou accomplie komunzki (KI -1) communément konsentimendu (MENDU) consentement konsolamendu (MENDU) consolation konsolatzaile (TZAILE) consolateur kontentamendu (MENDU) contentement kreatzaille (TZAILE) créateur laburzki (KI -1) brièvement langile (LE) ouvrier laxoki (KI -1) négligemment liberaltasun ((T)ASUN) générosité libreki (KI -1) librement liburutto (TO) petit livre lizuntasun ((T)ASUN) souillure, saleté lorifikatzaille (TZAILE) qui (se) glorifie maitatzaille (TZAILE) qui aime manamendu (MENDU) commandement merezimendu / mereximendu (MENDU) mérite miretsgarri (GARRI) admirable nagitasun ((T)ASUN) paresse 


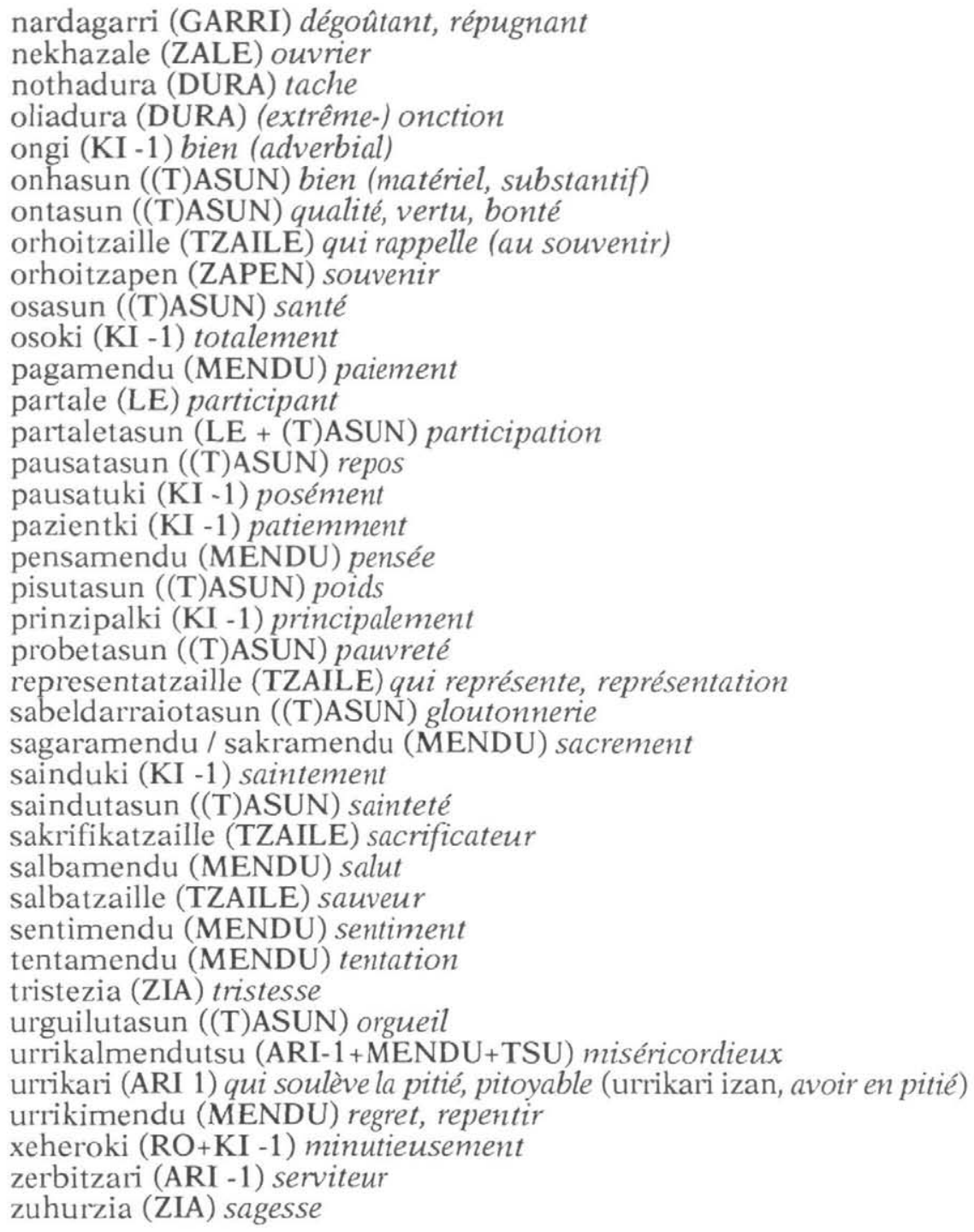




\section{Bibliographia}

Agirre, P. (bidean). Belapeyreren 'Catechima laburra'ren edizio kritikoa. EHUko doktore tesia.

Agud, M. \& Tovar, A. (1989-) Diccionario etimologico vaco, atalka ateratzen ari dena, in ASJU, Donostia. Oñati.

Axular, P. de -. (1643). Gero. Villasanteren edizioa, Jakin, 1976,

Azkarate, M. (1992). Oihenarten lexiko sorkuntza, in Oihenarten laugarren mendeurrena, Iker-8, Euskaltzaindia, Bilbo.

Azkue, R. M. de -. (1923-25). Morfologia vasca, in Euskera ; 1969.eko argitalpena, 3 liburukitan. Editorial la Gran Enciclopedia Vasca, Bilbo.

Belapeyre, A. (1696). Catechima laburra. J. L. Davantek paratu edizio kritikoa. 1983. Euskaltzaindia. Bilbo.

Bozas-Urrutia, R. (1968). Un 'Materre' de 1704, in BRSVAP, 24-2, 191-205.

Lafitte, P. (1944). Grammaire basque. 1962ko argitalpen berrikusi eta zuzendua. Ikas. Baiona.

Floristan Imizcoz, A. (1993). Conflictos fronterizos, espionaje y vascuence a finales del siglo XVI : 20 inéditos, in FLV, 63, 117-219.

Lakarra, J. (1994). Harrieten gramatikako hiztegiak, in ASJU, 18-1, 1-178, Donostia.

Materre, E. (1617.) Dotrina Christiana. 1623ko argitalpena (2.a). Iacques Millanges inprimatzailearen baitan, Bordele.

Michelena, L. (1960). Fonética Historica Vasca, 1976ko argitalpen zuzendu eta aberastua. ASJUren argitalpenak. Donostia.

Michelena, L. (1968). Aitonen, aitoren seme, 'noble hidalgo', in BAP, 24-3-18, berriz argitaratua in Sobre historia de la lengua vasca, II, 516527, Anejos del ASJU, 10 (1988).

Mitxelena, K. (1986). Eratorbidea eta deklinabidea, in Euskera, 21-2, 535-541. berriz argitaratua in Sobre historia de la lengua vasca, II, 674-679, Anejos del ASJU, 10 (1988).

OHE (Luis Michelena). Orotariko Euskal Hiztegia, atalka ateratzen ari dena, Euskaltzaindia, Bilbo.

Orpustan, J.-B. (1993). Oihenarten hiztegia. Éditions Izpegi, Baigorri.

Perez-Gaztelu, E. (1995). Egitasmoa eta egitatea. 2 liburuki. Errenteriako udala. Errenteria.

Rijk, R. de -. (1991). Deux suffixes capricieux : -PEN et -MEN, in Memoria L. Mitxelena Magistri Sacrum, Pars Altera, ASJU-ren gehigarriak. Donostia. 
Sarasola, I. (1984-1995). Hauta lanerako euskal hiztegia, 9 liburuki, Kutxa fondazioa, Donostia. Bilbo.

Trask, R. (1985). Ko atzizkia euskaraz, in Euskera, 30-1, 165-174,

Ühlenbeck C.C. (1909). Suffixes du basque servant à la dérivation des mots, in RIEV, 3,1-16, 192-225, 401-430).

Veyrin, P. (1943). Les Basques. 1975ko argitalpena. Arthaud, Paris.

Vinson, J. (1891) Essai d'une bibliographie de la langue basque. 1984 ko ASJUren argitalpena, Donostia.

Villasante, L. (1974). Palabras vascas compuestas y derivadas, Editorial franciscana Aranzazu, Oñati.

Zabala, I. \& Odriozola, J. C. (1994). 'Adjektiboen' eta 'adberbioen' arteko muga zehatzik eza, in ASJU, 28-2, 525-541, Donostia. 


\section{Résumé}

"La dérivation lexicale dans la Dotrina christiana [Doctrine chrétienne] de Materre (1617)", tel est le titre et l'objet de cette étude.

De manière préalable, l'article présente l'ouvrage de S. Materre qui est peu connu, car fort rare, du fait notamment de l'absence de réédition depuis bientôt trois siècles. Il s'agit pourtant, d'une part, du premier livre basque écrit en prose qui ne soit pas une traduction (même s'il faut tenir compte de la nature particulière de l'ouvrage : un livre d'instruction religieuse associé à un recueil de prières), d'autre part, de la première œuvre écrite en labourdin classique du XVII' siècle.

La chose est d'autant plus remarquable que l'auteur, un franciscain venu en Labourd après 1606, avait appris le basque à l'âge adulte et apparemment en l'espace de quelques années (il n'était plus en territoire basque en 1617) : c'est donc aussi le premier ouvrage écrit par un non-natif, et, pour dire vrai, s'il n'en avait pas fait la confidence dans un avertissement adressé aux Basques, c'est un fait que la seule lecture de l'ouvrage n'aurait probablement pas permis de déceler. La langue, en effet, est claire, naturelle, à la fois simple et de très bonne tenue, en tous points préfiguratrice de cette école labourdine dont l'œuvre d'Axular marque le sommet. Au demeurant, Materre, qui indique avoir appris le basque à Sare avait dû connaître Axular, curé de cette paroisse à cette époque, et l'on n'est donc pas surpris de voir figurer ce dernier parmi les examinateurs chargés de délivrer l'approbation épiscopale.

Concernant le sujet proprement dit de la recherche, le manque d'études relatives à la dérivation basque fondées sur les textes euxmêmes ayant été souligné, la dérivation lexicale est présentée dans la perspective de la création lexicale, et les buts de la recherche définis : rassembler de manière exhaustive, et classer, les dérivés lexicaux non verbaux formés par suffixation, de manière à cerner les contraintes de nature catégorielle régissant leur formation.

Après avoir défini la dérivation par rapport à la composition d'un côté et par rapport à la flexion de l'autre, les vocables dérivés se trouvant dans l'ouvrage de Materre sont recensés et regroupés par suffixes: 28 suffixes non verbaux sont étudiés, dont 10 ayant donné lieu à la formation d'au moins 3 vocables dans le corpus.

Au total 181 vocables sont dénombrés, chacun étant associé à un exemple illustrant son emploi. Les contraintes relatives à la catégorie grammaticale de la base à laquelle se joint chacun des suffixes, ainsi que leur propre nature catégorielle, sont définies, et certains cas particuliers discutés.

La liste des vocables est fournie en annexe, présentée dans l'ordre alphabétique, avec une traduction et l'indication du morphème de dérivation entre parenthèses. 